\title{
Observations of surface momentum exchange over the marginal ice zone and recommendations for its parametrisation
}

\author{
A. D. Elvidge ${ }^{1, \text { a }}$, I. A. Renfrew ${ }^{1}$, A. I. Weiss ${ }^{2}$, I. M. Brooks ${ }^{3}$, T. A. Lachlan-Cope ${ }^{2}$, and J. C. King ${ }^{2}$ \\ ${ }^{1}$ School of Environmental Sciences, University of East Anglia, Norwich, UK \\ ${ }^{2}$ British Antarctic Survey, Cambridge, UK \\ ${ }^{3}$ School of Earth and Environment, University of Leeds, Leeds, UK \\ ${ }^{a}$ present address: Atmospheric Processes and Parametrisations, Met Office, Fitzroy Road, Exeter, UK
}

Correspondence to: A. D. Elvidge (andy.elvidge@ metoffice.gov.uk)

Received: 17 August 2015 - Published in Atmos. Chem. Phys. Discuss.: 1 October 2015

Revised: 5 January 2016 - Accepted: 15 January 2016 - Published: 10 February 2016

\begin{abstract}
Comprehensive aircraft observations are used to characterise surface roughness over the Arctic marginal ice zone (MIZ) and consequently make recommendations for the parametrisation of surface momentum exchange in the MIZ. These observations were gathered in the Barents Sea and Fram Strait from two aircraft as part of the Aerosol-Cloud Coupling And Climate Interactions in the Arctic (ACCACIA) project. They represent a doubling of the total number of such aircraft observations currently available over the Arctic MIZ. The eddy covariance method is used to derive estimates of the $10 \mathrm{~m}$ neutral drag coefficient $\left(C_{\mathrm{DN} 10}\right)$ from turbulent wind velocity measurements, and a novel method using albedo and surface temperature is employed to derive ice fraction. Peak surface roughness is found at ice fractions in the range 0.6 to 0.8 (with a mean interquartile range in $C_{\mathrm{DN} 10}$ of 1.25 to $\left.2.85 \times 10^{-3}\right) . C_{\mathrm{DN} 10}$ as a function of ice fraction is found to be well approximated by the negatively skewed distribution provided by a leading parametrisation scheme (Lüpkes et al., 2012) tailored for sea-ice drag over the MIZ in which the two constituent components of drag - skin and form drag - are separately quantified. Current parametrisation schemes used in the weather and climate models are compared with our results and the majority are found to be physically unjustified and unrepresentative. The Lüpkes et al. (2012) scheme is recommended in a computationally simple form, with adjusted parameter settings. A good agreement holds for subsets of the data from different locations, despite differences in sea-ice conditions. Ice conditions in the Barents Sea, characterised by small, unconsolidated ice floes, are found to be associated with higher $C_{\mathrm{DN} 10}$
\end{abstract}

values - especially at the higher ice fractions - than those of Fram Strait, where typically larger, smoother floes are observed. Consequently, the important influence of sea-ice morphology and floe size on surface roughness is recognised, and improvement in the representation of this in parametrisation schemes is suggested for future study.

\section{Introduction}

Sea-ice movement is determined by five separate forces: a drag force from the atmosphere, a drag force from the ocean, internal sea-ice stresses, a downhill ocean-surface slope force, and the Coriolis force (e.g. Notz, 2012). The two drag forces are associated with a surface exchange of momentum across the atmosphere-ice or the ice-ocean boundary respectively. These exchanges impact the dynamical evolution of both atmosphere and ocean; here we focus on the interaction with the atmosphere only. Within the atmospheric surface layer (where the turbulent stress remains close to its surface value) the wind speed, $U(z)$, is related to the surface stress through

$U=\frac{u_{*}}{\kappa}\left[\ln \left(\frac{z}{z_{0}}\right)-\varphi\right]$,

where $u_{*}$ is the friction velocity, $\kappa$ is the von Karman constant (0.4), $z_{0}$ is the roughness length for velocity, and $\varphi$ is a stratification correction function (see, for example, Stull, 1988 for further details about this similarity theory approach). The aerodynamic roughness length, $z_{0}$, describes 
the level at which the wind speed described by Eq. (1) becomes 0 and represents the physical roughness of the surface (Stull, 1988). The momentum exchange (or wind stress) is then

$\tau=\rho u_{*}^{2}=\rho C_{\mathrm{D}} U^{2}$,

where $\rho$ is the density and $C_{\mathrm{D}}$ is the drag coefficient for the fluid at height $z$. Combining Eqs. (1) and (2) we can directly relate the drag coefficient and roughness length; for example, for neutrally stratified conditions and $z=10 \mathrm{~m}$,

$C_{\mathrm{DN} 10}=\left(\frac{u_{*}}{U_{10 \mathrm{~N}}}\right)^{2}=\frac{\kappa^{2}}{\ln \left(10 / z_{0}\right)^{2}}$.

Over a rough surface the drag has two components: a surface skin drag caused by friction and a form drag caused by pressure forces from the moving fluid impacting on roughness elements (Arya, 1973, 1975). The form drag acts on seaice ridges, on floe edges, on melt pond edges, and on surface undulations of all types. In other words, it is a function of the morphology of the sea ice and consequently it is strongly related to ice concentration and thickness.

To parametrise surface drag in numerical weather prediction, or climate or Earth system models, the above formulae are implemented to determine the surface stress for a given fluid velocity and stability ${ }^{1}$. To do this $C_{\mathrm{D}}$, or equivalently $z_{0}$, must be prescribed and so observations of these parameters for different sea-ice surfaces are required. To calculate these for the atmosphere-ice boundary, for example, observations of surface-layer momentum flux, wind speed, and atmospheric stability are required. These are challenging observations to make over sea ice and even more challenging over the marginal ice zone (MIZ).

Over the main sea-ice pack, with ice fraction, $A$, close to 1 , early studies based on tower or aircraft observations of turbulent fluxes estimated $C_{\mathrm{DN} 10}$ in the range $\sim 1-4 \times 10^{-3}$ for continuous sea ice, depending on the ice morphology. In a comprehensive review, Overland (1985) breaks down this range by morphology and location: for large flat floes $C_{\text {DN10 }}$ ranges $1.2-1.9 \times 10^{-3}$ and a median of $1.5 \times 10^{-3}$ is given (e.g. based on Banke and Smith, 1971 over the Canadian Arctic); for rough ice with pressure ridges $C_{\mathrm{DN} 10}$ ranges $1.7-3.7 \times 10^{-3}$; over first year ice in marginal seas (e.g. the Beaufort Sea or Gulf of St Lawrence) the $C_{\mathrm{DN} 10}$ subjective median values are $2.2-3.0 \times 10^{-3}$. More recently, Castellani et al. (2014) use airborne-derived laser altimeter data gathered between 1995 and 2011 in conjunction with a sea-ice drag parametrisation scheme to demonstrate the considerable topographic and geographic variability in $C_{\mathrm{DN} 10}$ over Arctic pack ice, with values ranging between 1.5 and $3 \times 10^{-3}$, largely corroborating the results of earlier studies.

\footnotetext{
${ }^{1}$ Note a turning angle between the fluid and the ice surface is also required if the surface-layer Ekman spiral is not resolved (Notz, 2012; Tsamados et al., 2014).
}

For the MIZ, data are not so readily available. On the "inner MIZ", with ice fractions of $0.8-0.9$ and consisting of small and rafted floes, Overland (1985) report only a few data sets, with $C_{\mathrm{DN} 10}$ in the range $2.6-3.7 \times 10^{-3}$; while for the "outer MIZ", with $A=0.3-0.4$, the only two values provided are $C_{\mathrm{DN} 10}=2.2$ and $2.8 \times 10^{-3}$ from MIZEX-1984 over the Greenland Sea (Overland, 1985) and from the Antarctic MIZ using an indirect balance method (Andreas et al., 1984). Further drag measurements over the MIZ using aircraft were made by Hartman et al. (1994) and Mai et al. (1996) as part of the "REFLEX" and "REFLEX II" experiments over Fram Strait. Hartman et al. (1994) obtained $16 C_{\mathrm{DN} 10}$ values with ranges of $C_{\mathrm{DN} 10}=1.0-2.3 \times 10^{-3}$ for $A=0.5-0.8$ and $C_{\mathrm{DN} 10}=1.1-1.6 \times 10^{-3}$ for $A=0.9-1.0$. They found generally higher $C_{\mathrm{DN} 10}$ values over ice fractions of $0.5-0.8$. Mai et al. (1996) found a similar range over their $8512-\mathrm{km}$ runs, with $C_{\mathrm{DN}}$ in the range $\sim 1.3 \times 10^{-3}$ over open water, to a maximum of $\sim 2.6 \times 10^{-3}$ at $A=0.5-0.6$, then decreasing to about $1.8 \times 10^{-3}$ for $A=1$. Schröder et al. (2003) largely corroborate these results with their 32 runs, finding a mean $C_{\mathrm{DN} 10}$ of $2.6 \times 10^{-3}$ for $A=0.5$ over Fram Strait and a mean $C_{\mathrm{DN} 10}$ of $1.6 \times 10^{-3}$ for $A=0.86$ over the Baltic Sea. These aircraft-based MIZ drag results are compiled together in Lüpkes and Birnbaum (2005). In short, they suggest that $C_{\mathrm{DN} 10}$ peaks over the MIZ $(A \approx 0.5-0.6)$ and decreases for lower or higher ice fractions.

Reviewing the above, however, it is clear that further surface drag measurements over the MIZ are critical for validating and developing parametrisations of surface exchange over sea ice. At present there are only about 150 individual data points for the MIZ from aircraft observations in the literature and the majority of these are from the same research group and platform. The majority were also made more than 20 years ago and, as has been well documented, Arctic sea ice is changing in extent and characteristics (e.g. Kwok and Rothrock, 2009; Markus et al., 2009). It is clear that new additional observations are urgently required. Improvements to the representation of sea ice are planned for many global weather forecasting models in order to aid both seasonal forecasting and shorter-term forecasting for the polar regions (e.g. ECMWF, 2013). These models typically have grid sizes of 10-25 km, meaning they will have the resolution to represent gradients in ice fraction across the MIZ and therefore need to parametrise MIZ interactions with the atmosphere. In addition, higher-resolution regional coupled atmosphere-ocean-ice models are providing improved skill and starting to be used operationally (Pellerin et al., 2004; Smith et al., 2013); while climate and Earth system models are also increasing in resolution and these will all require accurate surface exchange over the MIZ. Recent ocean-ice and atmosphere-ocean-ice modelling studies have demonstrated considerable sensitivity to surface exchange parametrisation over sea ice, particularly in their simulations of sea-ice thickness and extent (Tsamados et al., 2014; Rae et al., 2014) and the polar ocean (Stössel et al., 2008; Roy et al., 2015). Sim- 
ulations of the near-surface atmosphere can also be significantly affected (Rae et al., 2014).

Here we present over 200 new estimates of surface drag over the MIZ in Fram Strait and the Barents Sea from two independent research aircraft. This represents a more than doubling of the $C_{\mathrm{DN}}$ estimates currently available for surface exchange parameterisation development. Only low-level legs (mainly 30-40 m a.s.1.) are used to provide quality-controlled eddy covariance estimates of the turbulent momentum flux. We use these data to provide a validation of the leading parametrisation schemes and make recommendations for parameter settings. In the next section we present a brief review of surface exchange parametrisations. Section 3 covers data and methods and Sect. 4 presents our results. In Sect. 5 recommendations for the parametrisation of drag in the MIZ are made, before our conclusions in Sect. 6. Note that a summary of notation is provided at the end of the paper.

\section{Parametrising surface momentum exchange over sea ice}

\subsection{Background}

All atmospheric models require an exchange of momentum with the surface for accurate simulations. Over sea ice this has generally been treated rather crudely, usually with a constant drag coefficient prescribed for all sea-ice types and thicknesses (e.g. Notz, 2012; Lüpkes et al., 2013). For model grid boxes that are partially ice-covered a "mosaic method" is commonly employed, which typically calculates the flux over the ice and water surfaces separately, then averages these in proportion to the surface areas (e.g. Claussen, 1990; Vihma, 1995). Unfortunately, using this approach with a constant drag coefficient does not represent momentum exchange over the MIZ correctly. It results in a linear function of $C_{\mathrm{DN}}$ with $A$ rather than the maximum in drag at intermediate ice concentrations supported by observations.

Both empirical and physical-based parametrisations of surface drag have recently been developed. Andreas et al. (2010) composited together all available MIZ $C_{\mathrm{DN}}$ observations (primarily from Hartmann et al., 1994 and Mai et al., 1996) with the vast number of summertime sea-ice pack $C_{\mathrm{DN}}$ observations from the SHEBA project (Uttal et al., 2002) for $A>0.7$. They argued that summertime sea ice, replete with melt ponds and leads, was morphologically similar to the MIZ and so these data sets could be combined. Plotting $C_{\mathrm{DN}}$ against $A$, and ignoring various outliers, they found a maximum in $C_{\mathrm{DN}}$ around $A=0.6$. They empirically fitted by eye a second-order polynomial to this data set:

$$
10^{3} C_{\mathrm{DN}}=1.5+2.233 A-2.333 A^{2} .
$$

Here, $C_{\mathrm{DN}}$ is simply a function of ice fraction $(A)$, and other morphological characteristics are neglected.
A series of physical-based parametrisation schemes for surface drag has also been developed based on trying to capture the effect of form drag by equating sea-ice characteristics to roughness elements. The form drag is added to the skin drag to give a total surface drag, as represented in these schemes by

$C_{\mathrm{DN}}=(1-A) C_{\mathrm{DNw}}+A C_{\mathrm{DNi}}+C_{\mathrm{DNf}}$,

where $C_{\mathrm{DNw}}$ and $C_{\mathrm{DNi}}$ are the neutral skin drag coefficients over open water and continuous ice respectively, and $C_{\mathrm{DNf}}$ is the neutral form drag coefficient. This approach has its basis in work by Arya $(1973,1975)$ that has been developed and refined - see Hanssen-Bauer and Gjessing (1988), Garbrecht et al. (1999, 2002), Birnbaum and Lüpkes (2002), Lüpkes and Birnbaum (2005), Lüpkes et al. (2012), and Lüpkes and Gryanik (2015).

Amongst the leading MIZ drag schemes currently being implemented is that set out in Lüpkes et al. (2012; referred to hereafter as L2012). This scheme has been adapted for use in the Los Alamos sea-ice model CICE (Tsamados et al., 2014; Hunke et al., 2015). It determines neutral 10-m drag coefficients $\left(C_{\mathrm{DN} 10}\right)$ over 3 -dimensional ice floes as a function of sea-ice morphological parameters: sea-ice fraction as a minimum and, optionally, freeboard height and floe size. Lüpkes et al. (2013) illustrate the substantial impact such a parametrisation has on $C_{\mathrm{DN}}$ for summertime Arctic sea ice in contrast to the constant exchange coefficient approach that is currently standard in climate models.

\subsection{Derivation of form drag}

As a result of its sensitivity to sea-ice morphology, representing the form drag component of $C_{\mathrm{DN}}$ in a parametrisation scheme is a complex procedure. Its derivation in the L2012 scheme is best approached by considering a domain, of area $S_{\mathrm{t}}$, containing $N$ identical ice floes of cross-wind length $D_{\mathrm{i}}$ and freeboard height $h_{\mathrm{f}}$. If the area fraction of ice within the domain is given by $A$,

$S_{\mathrm{t}}=c_{\mathrm{s}} \frac{N D_{\mathrm{i}}^{2}}{A}$,

where $c_{\mathrm{S}}$ relates the deviation of the mean floe area from that of a square (so that $c_{\mathrm{s}}=1$ for a square and, for example, $c_{s}=\frac{\pi r^{2}}{4 r^{2}}=\frac{\pi}{4}$ for a circle). The total form drag acting on the frontal areas of ice floes within the domain is provided by

$$
f_{\mathrm{d}}=N c_{\mathrm{w}} S_{\mathrm{c}}^{2} D_{\mathrm{i}} \int_{z_{0 \mathrm{w}}}^{h_{\mathrm{f}}} \frac{\rho[U(z)]^{2}}{2} \mathrm{~d} z .
$$

Here, $c_{\mathrm{w}}$ is the fraction of the available force which effectively acts on each floe (Garbrecht et al., 1999); $S_{\mathrm{c}}$ is the sheltering function, which tends towards 0 for small distances between floes (implying a large sheltering effect) and tends 
towards 1 for large distances; $z_{0 \mathrm{w}}$ is the mean local roughness length over open water; and $U(z)$ is the upstream wind speed. Recall from Eq. (1) that $U(z)$ increases logarithmically with height, so the $10 \mathrm{~m}$ neutral wind speed is

$U_{\mathrm{N} 10}=\left(u_{*} / \kappa\right) \ln \left(10 / z_{0 \mathrm{w}}\right)$.

Noting that the surface wind stress due to form drag is simply the frontal force per unit area $\tau_{\mathrm{d}}=f_{\mathrm{d}} / S_{\mathrm{t}}, C_{\mathrm{DNf}}$ can be evaluated at the $10 \mathrm{~m}$ height according to Eqs. (3) and (8) as follows:

$C_{\mathrm{DN} 10 \mathrm{f}}=\frac{\tau_{\mathrm{d}}}{\rho U_{\mathrm{N} 10}^{2}}=\frac{f_{\mathrm{d}} / S_{\mathrm{t}}}{\rho\left(u_{*} / \kappa\right)^{2} \ln ^{2}\left(10 / z_{0 \mathrm{w}}\right)}$.

Equations (6) and (7) are inserted into Eq. (9), and the integral in Eq. (7) is solved with the aid of Eq. (8) to yield

$C_{\mathrm{DN} 10 \mathrm{f}}=A \frac{h_{\mathrm{f}}}{D_{\mathrm{i}}} S_{\mathrm{c}}^{2} \frac{c_{\mathrm{e}}}{2}\left[\frac{\left[\ln \left(h_{\mathrm{f}} / z_{0 \mathrm{w}}\right)-1\right]^{2}+1-2 z_{0 \mathrm{w}} / h_{\mathrm{f}}}{\ln ^{2}\left(10 / z_{0 \mathrm{w}}\right)}\right]$,

where the effective resistance coefficient $c_{\mathrm{e}}=c_{\mathrm{w}} / c_{\mathrm{s}}$. Finally, following the removal of insignificant terms in the above (resulting in a deviation typically less than $1 \%$ according to L2012), we obtain

$C_{\mathrm{DN} 10 \mathrm{f}}=A \frac{h_{\mathrm{f}}}{D_{\mathrm{i}}} S_{\mathrm{c}}^{2} \frac{c_{\mathrm{e}}}{2}\left[\frac{\ln ^{2}\left(h_{\mathrm{f}} / z_{0 \mathrm{w}}\right)}{\ln ^{2}\left(10 / z_{0 \mathrm{w}}\right)}\right]$.

\subsection{The L2012 parametrisation: equation summary}

The overall drag coefficient is the sum of the skin and form drag components, so substituting Eq. (1) into Eq. (5):

$$
\begin{aligned}
C_{\mathrm{DN} 10}= & (1-A) C_{\mathrm{DN} 10 \mathrm{w}}+A C_{\mathrm{DN} 10 \mathrm{i}} \\
& +A \frac{h_{\mathrm{f}}}{D_{\mathrm{i}}} S_{\mathrm{c}}^{2} \frac{c_{\mathrm{e}}}{2}\left[\frac{\ln ^{2}\left(h_{\mathrm{f}} / z_{0 \mathrm{w}}\right)}{\ln ^{2}\left(10 / z_{0 \mathrm{w}}\right)}\right] .
\end{aligned}
$$

Note that our Eqs. (11) and (12) are identical to L2012 Eqs. (51) and (22). L2012 defines $C_{\mathrm{DN} 10 \mathrm{w}}$ and $C_{\mathrm{DN} 10 \mathrm{i}}$ as skin drag terms. However, this assumes there is no form drag over open water or continuous sea ice, since the form drag contribution given by Eq. (11) only accounts for form drag on ice floe edges. In reality, additional form drag can be produced in the ocean due to waves, and over ice due to ridging and other roughness features caused by deformation and melt. Consequently, $C_{\mathrm{DN} 10 \mathrm{w}}$ and $C_{\mathrm{DN} 10 \mathrm{i}}$ are better expressed as the total (skin and form) drag over open water and continuous sea ice, respectively. The former is provided by

$C_{\mathrm{DN} 10 \mathrm{w}}=\kappa^{2} \ln ^{-2}\left(10 / z_{0 \mathrm{w}}\right)$,

using Eq. (3). Note that $z_{0 \mathrm{w}}$ is usually provided in models as a function of the surface stress on the sea surface and the gravitational restoring force via a modified Charnock relation

$z_{0 \mathrm{w}}=\alpha \frac{u_{*}^{2}}{g}+b \frac{v}{u_{*}}$, where $\alpha$ is the Charnock constant, $b$ is the smooth-flow constant, and $v$ is the dynamic viscosity of air (e.g. Fairall et al., 2003). L2012 set $\alpha=0.018$ and $b=0$. It is more common to include the smooth-flow term, usually with $b=0.11$, so that there is some momentum exchange at low wind speeds (e.g. Renfrew et al., 2002; Fairall et al., 2003). The first term leads to an increase in roughness, and hence drag coefficient, as the wind speed increases. This increase is related to waveinduced roughness and is now reasonably well constrained for low to moderate wind speeds, but there is some uncertainty at higher wind speeds (Fairall et al., 2003; Petersen and Renfrew 2009; Cook and Renfrew 2015). Various values for the Charnock "constant" are used, typically between 0.011 and 0.018. In the Fairall et al. (2003) review they suggest that $\alpha$ should linearly increase from 0.011 to 0.018 (between $\left.U_{\mathrm{N} 10}=10-18 \mathrm{~m} \mathrm{~s}^{-1}\right)$, although they note some uncertainty in $\alpha$ for $U_{\mathrm{N} 10}$ above $10 \mathrm{~m} \mathrm{~s}^{-1}$.

For the drag over continuous ice, L2012 recommend $C_{\text {DN10i }}=1.6 \times 10^{-3}$. This is consistent with the range of values for the total drag over large flat floes, $C_{\mathrm{DN}}=1.2-$ $1.9 \times 10^{-3}$, given in Overland (1985) making the assumption that the form drag over flat floes is negligible. This choice for $C_{\text {DN10i }}$ is also typical of the values commonly set in numerical models (Lüpkes et al., 2013).

L2012 provides three formulations for the sheltering function, $S_{\mathrm{c}}$. The form chosen for the CICE model (Tsamados et al., 2014) is

$S_{\mathrm{c}}=\left(1-\exp \left(-s \frac{D_{\mathrm{w}}}{h_{\mathrm{f}}}\right)\right)$

where $s$ is a dimensionless constant and the distance between floes, $D_{\mathrm{w}}=D_{\mathrm{i}}(1-\sqrt{A}) / \sqrt{A}$ (after Lüpkes and Birnbaum, 2005). Equations (12)-(15) together with the recommended parameters set out in Table 1 establish the parametrisation of $C_{\mathrm{DN} 10}$ as a function of $A, h_{\mathrm{f}}, D_{\mathrm{i}}$, and $u_{*}$. In many models, however, freeboard heights and floe lengths are not available. In this instance, L2012 provides further simplifications to present both $h_{\mathrm{f}}$ and $D_{\mathrm{i}}$ in terms of $A$ :

$h_{\mathrm{f}}=h_{\max } A+h_{\min }(1-A)$,

$D_{\mathrm{i}}=D_{\min }\left(\frac{A_{*}}{A_{*}-A}\right)^{\beta}$,

where

$A_{*}=\frac{1}{1-\left(D_{\min } / D_{\max }\right)^{1 / \beta}}$

and $\beta$ is a tuning constant. Recommended values for the constant parameters $h_{\min }, h_{\max }, D_{\min }, D_{\max }$, and $\beta$ are provided in Table 1, taken from an analysis of laser altimeter observations of these summarised in L2012. 
Table 1. Parameter settings for the form drag component of the L2012 scheme (Lüpkes et al., 2012): as recommended in L2012, as used in CICE (Tsamados et al., 2014), and as recommended here (E2016A and E2016B).

\begin{tabular}{lrrrrrrr}
\hline & $c_{\mathrm{e}}$ & $s$ & $D_{\min }$ & $D_{\max }$ & $h_{\min }$ & $h_{\max }$ & $\beta$ \\
\hline L2012 & 0.3 & 0.5 & $8 \mathrm{~m}$ & $300 \mathrm{~m}$ & $0.286 \mathrm{~m}$ & $0.534 \mathrm{~m}$ & 1 \\
CICE & 0.2 & 0.18 & $8 \mathrm{~m}$ & $300 \mathrm{~m}$ & $0.286 \mathrm{~m}$ & $0.534 \mathrm{~m}$ & 1 \\
E2016A & 0.17 & 0.5 & $8 \mathrm{~m}$ & $300 \mathrm{~m}$ & $0.286 \mathrm{~m}$ & $0.534 \mathrm{~m}$ & 1 \\
E2016B & 0.1 & 0.5 & $8 \mathrm{~m}$ & $300 \mathrm{~m}$ & $0.286 \mathrm{~m}$ & $0.534 \mathrm{~m}$ & 0.2 \\
\hline
\end{tabular}

\section{Data collection and methodology}

\subsection{Data collection and aircraft instrumentation}

The data used for this study are from research flights over the Arctic MIZ using two aircraft: a DHC6 Twin Otter operated by the British Antarctic Survey and equipped with the Meteorological Airborne Science INstrumentation (MASIN) and the UK Facility for Airborne Atmospheric Measurement (FAAM) BAe-146. Data from eight flights are used here, conducted between 21 and 31 March 2013 as part of the first ACCACIA (Aerosol-Cloud Coupling and Climate Interactions in the Arctic) field campaign. The relevant flight legs are located both to the northwest of Svalbard over Fram Strait and southeast of Svalbard in the Barents Sea (Fig. 1). Wintertime sea ice in the Barents Sea is relatively thin and, owing to a cool southward-flowing surface ocean current and cyclone activity in the region, tends to extend further south than in Fram Strait where the warm North Atlantic Current has a greater influence (Johannessen and Foster, 1978; Sorteberg and Kvingedal, 2006).

To estimate surface momentum flux from the aircraft requires high-frequency measurements of wind velocity and altitude, along with an estimate of atmospheric stability. To measure 3-D winds the MASIN Twin Otter uses a nine-port Best Aircraft Turbulence (BAT) probe (Garman et al., 2006) mounted on the end of a boom above the cockpit and extending forward of the aircraft's nose; while the BAE146 uses a five-port radome probe on the nose of the aircraft. To measure altitude at low levels both aircraft use radar altimeters. To measure air temperatures both aircraft use Rosemount sensors (non-deiced and deiced), while to measure sea surface temperature (SST) both aircraft use Heimann infrared thermometers. For the calculation of albedo (used to derive estimates of sea-ice concentration), both aircraft use Eppley PSP pyranometers to measure shortwave radiation. Further details about the instrumentation - calibration, sampling rate, resolution, and accuracy - can be found in King et al. (2008) and Fiedler et al. (2010) for the MASIN Twin Otter, and in Renfrew et al. (2008) and Petersen and Renfrew (2009) for turbulence measurements on the BAE146. For brevity these details are not reproduced here.

In general, the aircraft measurements are processed identically. One exception is in the calibration of SST. Here the

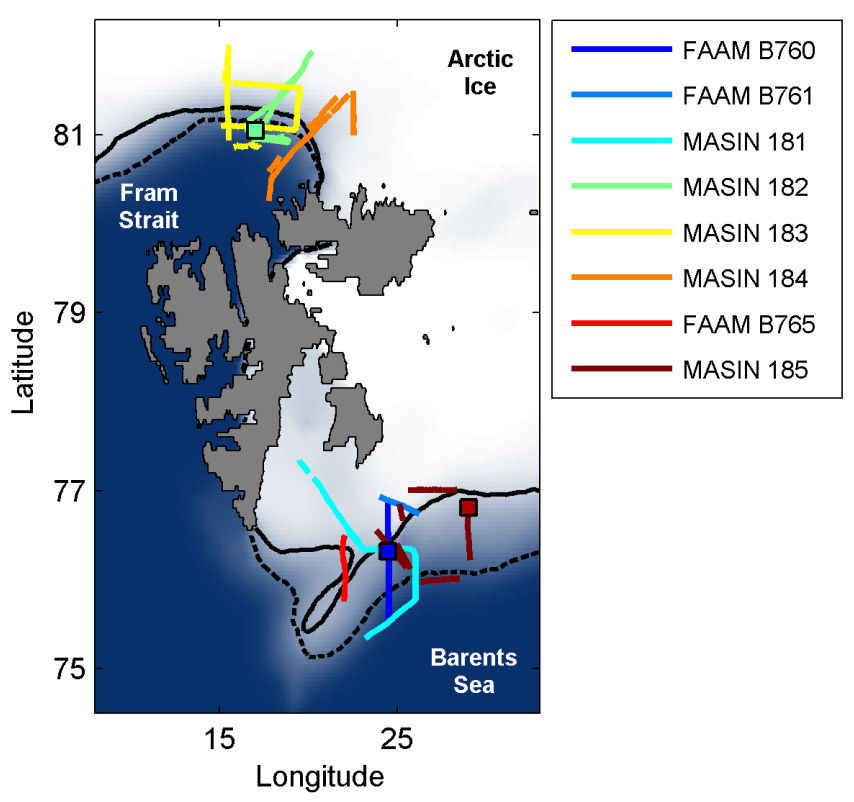

Figure 1. Map of Svalbard (landmass in grey) and the surrounding ocean and sea ice. The blue-white shading conveys the mean sea-ice fraction from the satellite-derived Operational Sea Surface and Sea Ice Analysis (OSTIA) for the March 2013 field campaign, while contours at 0.5 ice fraction illustrated the maximum (dashed black) and minimum (solid black) extents. The relevant flight legs are plotted in colour and listed in chronological order in the legend. Coloured squares show the locations of the images shown in Figs. 5 and 6.

MASIN Twin Otter uses black-body calibrations in conjunction with corrections for emissivity based on SST measurements of the same surface at different altitudes, whereas for the BAE146 the Heimann infrared SST is adjusted by a constant offset for each flight determined by the ARIES (Airborne Research Interferometer Evaluation System) instrument, which can estimate the emissivity accurately by rotating the field of view in flight, thus obtaining very accurate SST estimates (see Newman et al., 2005; or Cook and Renfrew, 2015 for a discussion).

\subsection{Derivation of surface drag coefficients from the aircraft observations}

To estimate flight-level momentum flux - from which $C_{\mathrm{DN} 10}$ may be derived - we use the well-established eddy covariance method. This is commonly used in aircraft-based flux research (e.g. French et al., 2007) and has previously been used with both MASIN data (e.g. Fiedler et al., 2010; Weiss et al., 2011) and FAAM data (e.g. Petersen and Renfrew, 2009; Cook and Renfrew, 2015). It requires that flight legs are straight and level and conducted as close to the surface as is logistically feasible (the vast majority of our data were measured at heights under $40 \mathrm{~m}$ - see Table 2). These flight legs are then divided into flux runs of equal duration, with 
Table 2. Summary of flights during the March 2013 ACCACIA field campaign. Flight numbers preceded by the letter "B" use the FAAM BAE146; the other flights use the MASIN Twin Otter.

\begin{tabular}{lrrrrrrl}
\hline Date & $\begin{array}{r}\begin{array}{r}\text { Flight } \\
\text { no. }\end{array} \\
\text { legs }\end{array}$ & $\begin{array}{r}\text { No. } \\
\text { runs }\end{array}$ & $\begin{array}{r}\text { No. "good" } \\
\tau \text { runs }\end{array}$ & $\begin{array}{r}\text { Mean altitude } \\
(\mathrm{m} \text { a.m.s.l. })\end{array}$ & $\begin{array}{r}\text { Mean wind speed } \\
\left(\mathrm{m} \mathrm{s}^{-1}\right)\end{array}$ & $\begin{array}{l}\text { Flight } \\
\text { location }\end{array}$ \\
\hline 21-Mar & B760 & 1 & 18 & 17 & 79 & 7.8 & Barents Sea \\
22-Mar & B761 & 1 & 7 & 7 & 38 & 7.4 & Barents Sea \\
23-Mar & 181 & 6 & 40 & 37 & 36 & 8.3 & Barents Sea \\
25-Mar & 182 & 6 & 37 & 33 & 39 & 7.2 & Fram Strait \\
26-Mar & 183 & 7 & 36 & 34 & 29 & 7.2 & Fram Strait \\
29-Mar & 184 & 6 & 30 & 29 & 33 & 6.9 & Fram Strait \\
30-Mar & B765 & 1 & 9 & 9 & 41 & 8.9 & Barents Sea \\
31-Mar & 185 & 8 & 32 & 29 & 33 & 4.9 & Barents Sea \\
\hline
\end{tabular}

velocity perturbations calculated from linearly detrended run averages. The flight-level momentum flux $(\tau)$ for each run is calculated from the covariance between the perturbation of the horizontal wind components from their means $\left(u^{\prime}, v^{\prime}\right)$ and that of the vertical wind component $\left(w^{\prime}\right)$ as follows:

$\tau=\bar{\rho} \sqrt{{\overline{u^{\prime} w^{\prime}}}^{2}+{\overline{v^{\prime} w^{\prime}}}^{2}}$

where $\bar{\rho}$ is the mean run air density. It is assumed that the measurements are made in the surface layer, and that this is a constant-flux layer so $\tau$ is not adjusted for height (see Petersen and Renfrew, 2009 for a discussion). For the great majority of flights, a mean altitude of $\sim 34 \mathrm{~m}$ suggests that this is a good assumption. Even so, despite this assumption being widely adopted and generally accepted as necessary, its accuracy is a point of contention (see Garbrecht et al., 2002) and is an issue for future work. The surface roughness length, $z_{0}$, is derived using Eqs. (1) and (2). The stability correction $\varphi$ in Eq. (1) is an empirically derived function of $z$ and the Obukhov length, $L$, a parameter related to stratification. We use the corrections of Dyer (1974) for stable conditions and Beljaars and Holtslag (1991) for unstable conditions. The neutral drag coefficient at $10 \mathrm{~m}\left(C_{\mathrm{DN} 10}\right)$ is then evaluated for each run via Eq. (3).

Each flux run is subject to a quality control procedure, details of which can be found in Appendix A. Through this quality control procedure, it was determined that a flux-run length of $\sim 9 \mathrm{~km}$ was optimum. For this run length, 14 from the total 209 runs available are rejected following quality control, which leaves a total of 195 usable flux runs.

In order to test our observations against the L2012 parametrisation described in Sect. 2, an estimate of the ice fraction $A$ is required. For this, two methods have been developed using the simultaneous aircraft observations: the first uses albedo (from shortwave radiation); the second uses SST (from the downward infrared thermometer with some adjustments based on the albedo). The sensitivity to choices made in our estimation of $A$ in both approaches is tested via the adoption of two different criteria - one based on flight video evidence, the other based on theory. For detailed description of our methodology for estimating A please see Appendix B.

\section{Results}

\subsection{Complete data set}

Our observations enable investigation into the relationship between sea-ice drag and ice fraction. Figure 2 shows $C_{\mathrm{DN} 10}$ plotted as a function of $A$ for all flux-runs and for all methods used to derive $A$ (see Appendix B). These are ice fraction derived via albedo $\left(A_{\mathrm{a}}\right)$ and via surface temperature $\left(A_{\mathrm{SST}}\right)$ using no ice transition tie points set according to inspection of our in-flight videos and also to values expected theoretically $\left(A_{\mathrm{SST} 2}\right)$ or as previously observed $\left(A_{\mathrm{a} 2}\right)$. The observational data are partitioned into ice fraction bins using intervals in $A$ of 0.2 (corresponding to a total of six bins). This interval was chosen as it permits a relatively large number of data points in each bin (between 11 and 65; see Fig. 2), whilst providing a sufficient number of bins to assess the sensitivity of $C_{\mathrm{DN} 10}$ to $A$. The distribution of values within each bin is represented by the median, the interquartile range, and the 9th and 91st percentiles.

In all four panels in Fig. 2, the lowest median drag coefficients are found at the upper and lower limits of ice fraction (in the $A=0,0.2$, and 1 bins), whilst the highest median drag coefficients are in the 0.6 and 0.8 bins. This describes a unimodal, negatively skewed distribution (i.e. with a longer tail towards lower $A$ ). This distribution qualitatively conforms to the L2012 parametrisation using typical parameter settings (this is revisited in Sect. 4.3). Across all ice fractions our results lie within the range of those obtained in previous studies (see review in Sect. 1 and Andreas et al., 2010).

The small interquartile range in $C_{\mathrm{DN} 10}$ evident in Fig. 2 in the $A=0$ bin reflects the small variability in wind velocity during the field campaign, with run-averaged wind speeds averaging $7 \mathrm{~m} \mathrm{~s}^{-1}$ (close to the climatological mean for the Arctic summer), peaking at $13 \mathrm{~m} \mathrm{~s}^{-1}$ (see Table 2) and being from a generally consistent direction (northerly, i.e. off- 

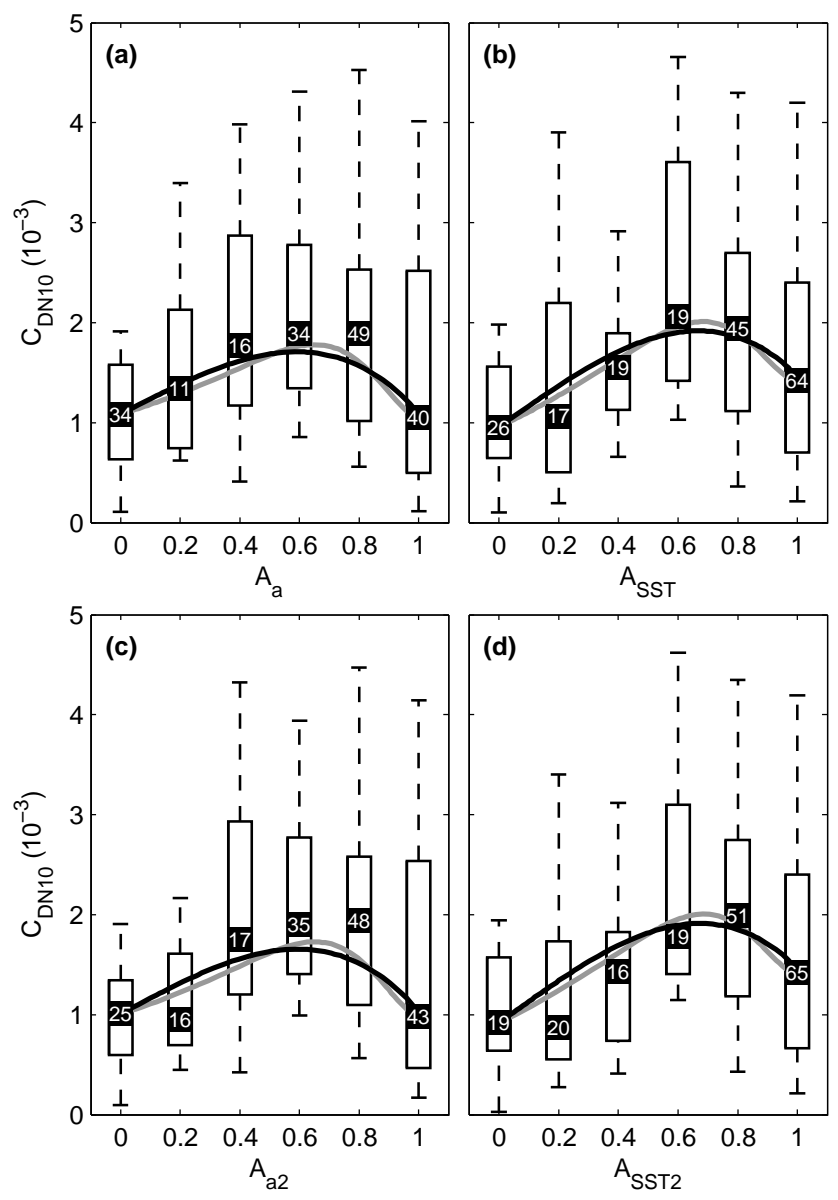

Figure 2. $C_{\mathrm{DN} 10}$ as a function of ice fraction $A$ : (a) $A_{\mathrm{a}}$ (from albedo); (b) $A_{\mathrm{SST}}$ (from sea surface temperature with a no ice transition at $-3.4{ }^{\circ} \mathrm{C}$; (c) $A_{\mathrm{a} 2}$ (from albedo with alternative tie points); and (d) $A_{\mathrm{SST} 2}$ (from SST with a no ice transition at $-1.8^{\circ} \mathrm{C}$ ). $\mathrm{Ob}-$ servational data are arranged in ice fraction bins of interval 0.2. Box and whisker plots show the median (black square), interquartile range (boxes), and 9th and 91st percentiles (whiskers) within each bin. The number of data points within each bin is indicated at the bin-median level. The L2012 scheme is illustrated by curves anchored at our observed values for $A=0$ and $A=1$, using parameter settings E2016A (black curve) and E2016B (grey curve) in Table 1.

ice). Note that over the open ocean (away from ice), surface roughness is a strong function of wave height and therefore wind speed. Our bin-averaged $C_{\mathrm{DN} 10}$ values over open sea water compare well with those expected by inputting observed wind speeds into the well-established COARE bulk flux algorithm of Fairall et al. (2003). Values derived from COARE Version 3.0 consistently lie within the interquartile range.

For data points over continuous ice $(A=1)$ our observed median values of $C_{\mathrm{DN} 10}$ are towards the lower end of the range for large flat floes given in Overland (1985) of 1.2-3.7. However, relative to that for $C_{\mathrm{DN} 10 \mathrm{w}}$, there is a high degree of variability in $C_{\mathrm{DN} 10 \mathrm{i}}$ within bins. This reflects significant

heterogeneity in ice conditions and hence roughness, as previously discussed (e.g. Overland, 1985), and as was visually apparent from the aircraft throughout our field campaign. For this reason, over uninterrupted ice $C_{\mathrm{DN} 10}$ is region specific, unlike over open water. In our observations these values are indeed found to vary systematically and considerably with location and this is investigated further below. Even greater scatter in $C_{\mathrm{DN} 10}$ is apparent within the intermediate ice fraction bins $(0.2,0.4,0.6$ and 0.8$)$ as form drag here is affected not only by variability in ice roughness, but also by variability in the frontal area of floes (governed by floe size and freeboard height). Furthermore, the upper limit of ice roughness is likely to be greater here due to deformation as a result of waves and floe advection (Kohout et al., 2014).

It is apparent from Fig. 2 that our results are qualitatively similar for all derivations of $A$. In particular, apart for some minor shifts in $C_{\mathrm{DN} 10}$ due to the rearrangement of data points between adjacent bins, the impact of varying the no ice transition tie point is small - compare panel (a) with panel (c) and panel (b) with panel (d). This implies that our results are relatively robust.

\subsection{Variability within the data set}

To further explore the observed sensitivity of $C_{\mathrm{DN} 10}$ with $A$ as well as the scatter in $C_{\mathrm{DN} 10}$ within ice fraction bins, we now focus on subsets of the data. Given the dependence of surface roughness not only on ice fraction but also on sea-ice properties, a logical divide would be based on location. As is apparent in Fig. 1, the flights were conducted either to the northwest of Svalbard in Fram Strait or to the southeast of Svalbard in the Barents Sea. Conveniently, this split apportions approximately equal numbers of data points to each location. Results from Fram Strait are shown in Fig. 3, whilst those from the Barents Sea are shown in Fig. 4. Given the lack of sensitivity of results to varying the no ice transition tie point, only $A_{\mathrm{a}}$ and $A_{\mathrm{SST}}$ are shown here.

Significant differences in the distribution of $C_{\mathrm{DN} 10}$ as a function of $A$ for these two locations are apparent, especially towards the higher ice fractions. The Barents Sea is characterised by far greater values of $C_{\mathrm{DN} 10}$ for $A \geq 0.6$, with median $C_{\mathrm{DN} 10} \approx 2.5 \times 10^{-3}$ at $A=1$, compared to less than $1.2 \times 10^{-3}$ in Fram Strait (note that at lower ice fraction there is more consistency in $C_{\mathrm{DN} 10}$ between the locations). These differences imply rougher sea-ice conditions in the Barents Sea, a result that might be expected given the typically thinner ice, a less sharp ocean-ice transition here (i.e. a geographically larger MIZ, see Fig. 1), and greater variability in the position of the ice edge in the Barents Sea during the field campaign - suggestive of ice melt, deformation, and changeable ice conditions. Such heterogeneity is reflected by the considerably greater scatter in $C_{\mathrm{DN} 10}$, whilst the wider MIZ is implied by a considerably larger proportion of data points residing within the intermediate ice fraction bins $(0.2,0.4$, 

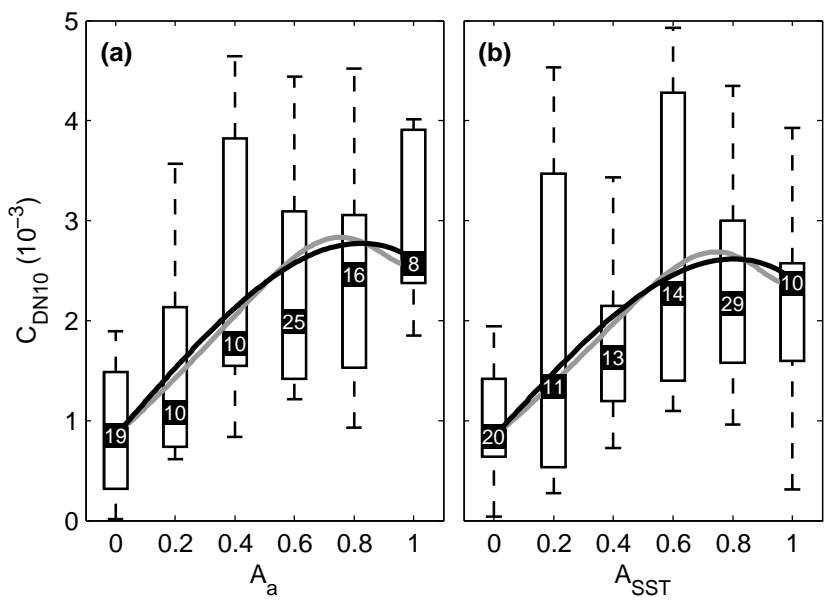

Figure 3. As in Fig. 2, but for Barents Sea flights only (see Table 2 for details of flights).
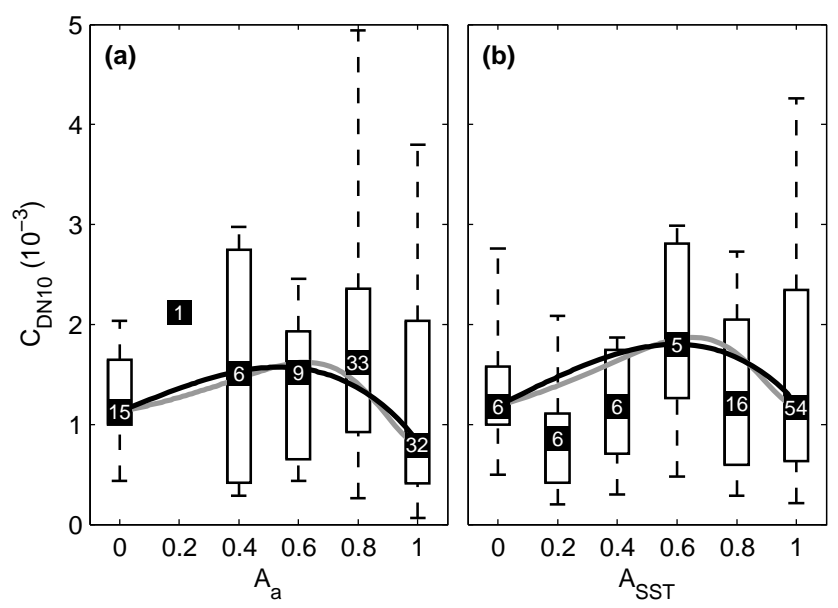

Figure 4. As in Fig. 2, but for Fram Strait flights only (see Table 2 for details of flights).

0.6, and 0.8) for the Barents Sea data (around 69\%) compared to Fram Strait data (35-51\%).

The systematic differences in ice conditions between these locations are also apparent in flight videos and photographs. Figure 5 shows images from two Barents Sea flights: a photograph from the port-side of the FAAM aircraft during Flight B760 and a still taken from the forward-looking video camera 10 days later during MASIN Flight 185 (see Fig. 1 for image locations). Each of these images is representative of sea-ice conditions associated with the highest individual values of $C_{\mathrm{DN} 10}$ observed during each flight (4.7 and $5.7 \times 10^{-3}$ respectively) and correspond to ice fractions of $\sim 0.8$ and $\sim 0.6$, respectively. The ice morphology depicted in the two photos is comparable, constituting relatively small, broken floes (of order tens of metres in scale) with raised edges implying collisions between the floes. Whilst evidently
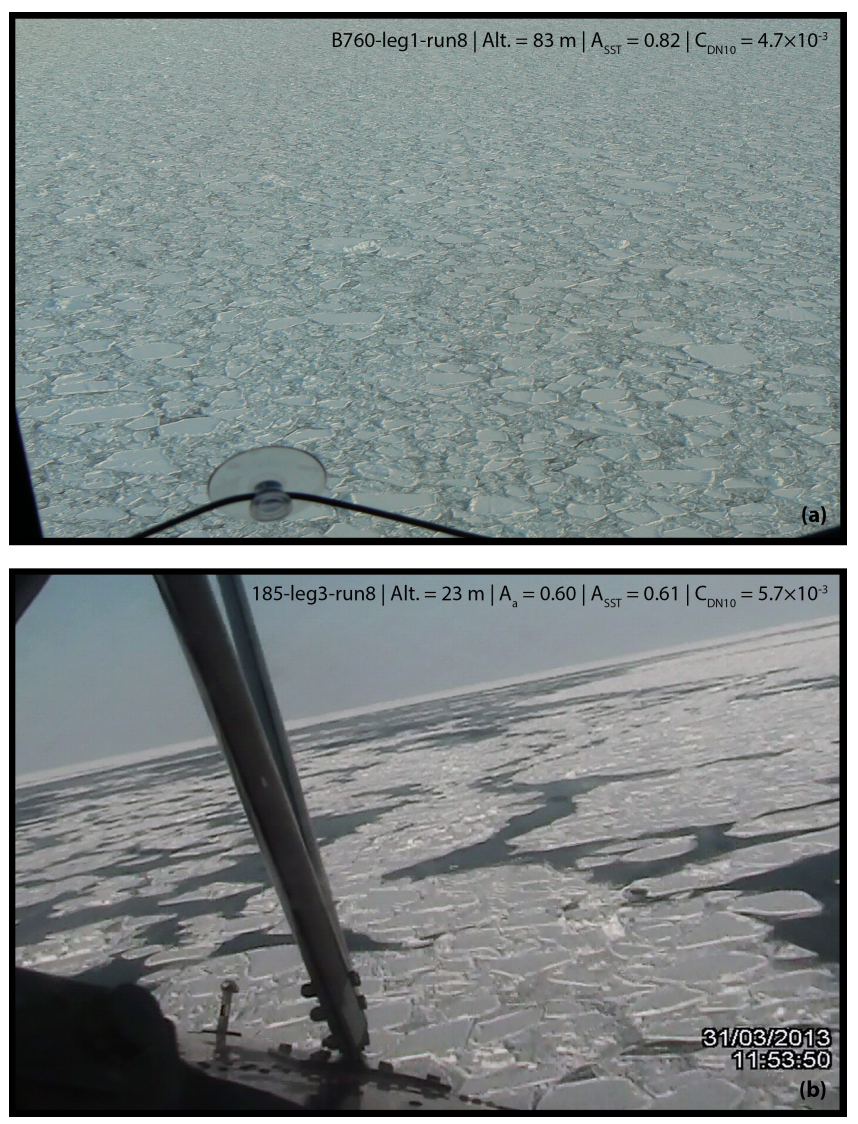

Figure 5. (a) Photograph taken from the FAAM aircraft during Flight B760 flux-run marked with an arrow in Fig. 7; and (b) still from video recorded from the MASIN aircraft during Flight 185. The image locations are marked in Fig. 1.

widespread in the Barents Sea MIZ, such conditions are not apparent in video footage and photographs made during two of the three Fram Strait flights (182 and 183). During these flights, ice morphology in the MIZ appears quite different: consisting of larger floes often separated by large leads and a more distinct ice edge (as depicted for Flight 182 in Fig. 6). The jagged, small floes illustrated in Fig. 5 are associated with high $C_{\mathrm{DN} 10}$ values. Such conditions in the wintertime MIZ resemble dynamically rough summertime melt-season ice (Andreas et al., 2010), and smaller floes are associated with greater drag due to an increased frontal area. Note that this roughness extends to the highest ice concentrations (in the $A=1$ bin; Fig. 3), despite the fact that floe sizes will tend to increase as $A$ approaches 1 . This is perhaps unsurprising: the photographs of Fig. 5 show that where floes have been fused together - giving a local ice fraction of 1 - the ice noticeably retains its rough, deformed characteristics. Video footage from the third Fram Strait flight (Flight 184) reveals ice conditions more like those observed in the Barents Sea, and indeed this flight was associated with greater drag coefficients than the other two - comparable to those of the Barents 


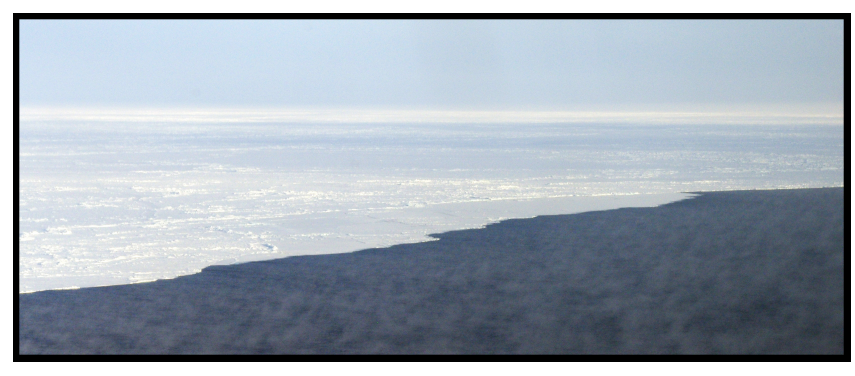

Figure 6. Photograph taken from the MASIN aircraft between legs 3 and 4 during Flight 182 at an altitude of $\sim 100 \mathrm{~m}$. The location is marked in Fig. 1.

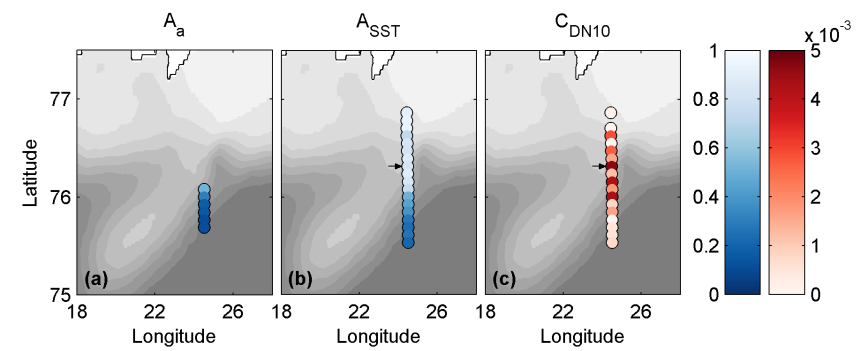

Figure 7. Spatial maps of ice fraction (a) $A_{\mathrm{a}}$, (b) $A_{\mathrm{SST}}$, and (c) drag coefficient $C_{\mathrm{DN} 10}$ for all flux-runs during FAAM Flight B760. The background greyscale shading is OSTIA sea-ice concentration (lighter shades indicating higher ice concentrations).

Sea flights. Note that whilst the relevant Flight 182 and 183 legs overlap, Flight 184 was conducted further east (Fig. 1).

To delve more deeply into the relationship between $C_{\mathrm{DN} 10}$ and ice fraction, we now examine two particular flights one from each research aircraft. We focus on the flights with the greatest number of $f$ lux-runs from each aircraft: FAAM Flight B760 and MASIN Flight 181 (Table 2). Figures 7 and 8 show distributions of $A_{\mathrm{a}}, A_{\mathrm{SST}}$, and $C_{\mathrm{DN} 10}$ for all flux-runs in map form for both flights. Note there is generally good agreement between $A_{\mathrm{a}}$ and $A_{\mathrm{SST}}$ where data are available for both (a pyranometer malfunction during B760 limits the availability of $A_{\mathrm{a}}$ ). In Flight 181, the aircraft traversed the relatively broken ice immediately southeast of Svalbard, and over the ice edge and open water further south. The B760 leg traversed north-south over the ice edge at a similar location. From these figures it is apparent that in general the highest values of $C_{\mathrm{DN} 10}$ relate to MIZ conditions. This is especially clear for Flight B760, due to the simple gradient in ice fraction; towards the south, $C_{\mathrm{DN} 10}$ is small over open water; moving northward over the MIZ $C_{\mathrm{DN} 10}$ increases and exhibits more variability, reflecting typically heterogeneous ice conditions in the MIZ, and for the northernmost runs $C_{\mathrm{DN} 10}$ decreases again as more consolidated pack ice is encountered (Fig. 7). As discussed above, sea-ice conditions during the B760 flux-run for which peak $C_{\mathrm{DN} 10}$ is observed (arrow in Fig. 7) are captured in the photograph shown in Fig. 5a.
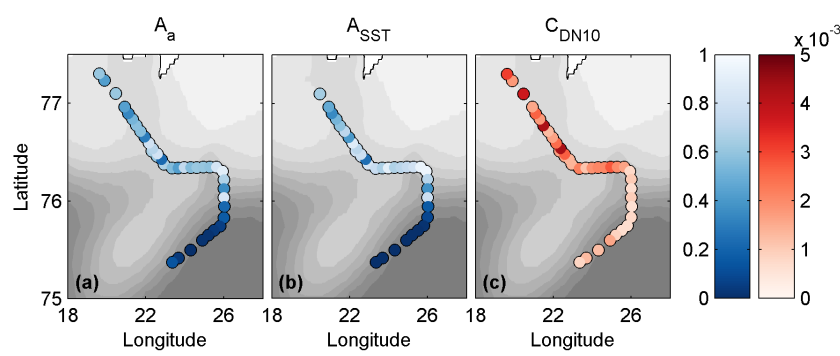

Figure 8. Spatial maps of ice fraction (a) $A_{\mathrm{a}}$, (b) $A_{\mathrm{SST}}$, and (c) drag coefficient $C_{\mathrm{DN} 10}$ for all flux-runs during MASIN Flight 181, as Fig. 7.

Figure 9 shows $C_{\mathrm{DN} 10}$ as a function of $A$ for Flight 181 . The distribution is similar to that described previously, with $C_{\text {DN10 }}$ peaking in the $A=0.6$ and 0.8 bins. Comparing Fig. 9 with Fig. 3 shows that drag coefficients are towards the lower end of the range for the Barents Sea. Note that a similar plot is not shown for Flight B760 due to the sparsity of data. Of all our flights only 181 provides sufficient data across the range of ice fractions to make presentation in this form worthwhile.

\subsection{Validation and modifications to the $\mathbf{L 2 0 1 2}$ parametrisation}

The curves shown in Figs. 2, 3, 4, and 9 represent the L2012 parametrisation. They result from setting the observed median $z_{0 \mathrm{w}}, C_{\mathrm{DN} 10 \mathrm{w}}$, and $C_{\mathrm{DN} 10 \mathrm{i}}$ in Eq. (12) - to fix the end points of the curves - then adopting new parameter settings for the form component of drag, $C_{\mathrm{DN} 10 \mathrm{f}}$. These were chosen to provide a good fit to our observational results whilst also largely satisfying previously gathered empirical evidence. In fact, the parameter settings recommended by L2012 provide a near-satisfactory fit to our observations, and only minor optimization is recommended.

Of the parameters dictating the form component of the drag coefficient $\left(C_{\mathrm{DN} 10 \mathrm{f}}\right.$; see Eq. 11$), h_{\min }, h_{\max }, D_{\min }$, $D_{\max }$, and $\beta$ are all appointed in L2012 according to previous observations. Values assigned to the effective resistance coefficient $c_{\mathrm{e}}$ and sheltering parameter $s$ are considerably less well verified, making them preferential for tuning. Increasing $s$ from the value recommended in L2012 such as to bring about a better fit to our data has minimal effect on $C_{\mathrm{DN} 10}$ for all but the highest ice fractions, whereas, as evident from Eq. (12), $C_{\mathrm{DN} 10}$ is equally sensitive across the full range of $A$ to changes in $c_{\mathrm{e}}$. Reducing $c_{\mathrm{e}}$ from 0.3 to 0.17 and keeping all other parameters as recommended in L2012 (E2016A in Table 1) provides a generally good fit to our observations and this is illustrated by the black curved lines in Figs. 2, 3, 4 , and 9. This curve passes close to median values and comfortably through the interquartile range of all ice fraction bins in Fig. 2, demonstrating the skill of the L2012 parametrisation in capturing the sensitivity of $C_{\mathrm{DN} 10}$ to $A$ when averaged over a large data set. 

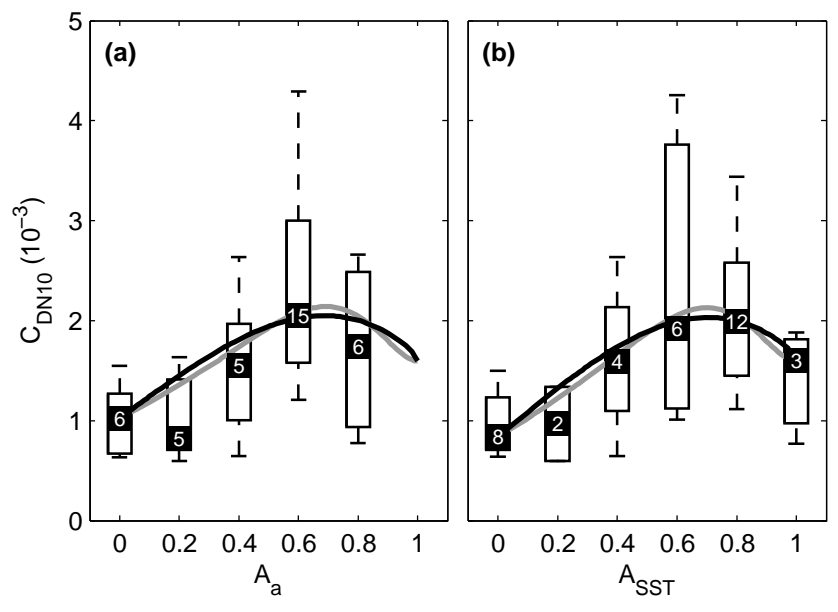

Figure 9. As in Fig. 2, but for Flight 181 only (see Table 2 for flight details).

The fit using the E2016A settings is not perfect. In particular, there is a suggestion that for the full data set (Fig. 2) $C_{\mathrm{DN} 10}$ is underestimated at high ice fraction (the $A=0.8$ and 0.6 bins) and overestimated at $A=0.2$. As indicated by our results and those of previous studies, $C_{\mathrm{DN} 10}$ at high ice fractions is governed by sea-ice morphology and as such its variability is large and location dependent. Consequently, discrepancies here are unsurprising. A possible explanation for the overestimate at lower ice fractions is that the parametrisation does not take into account the attenuating effect of sea ice on waves (e.g. Wadhams et al., 1988). To compute the form drag coefficient (Eq. 11) we use observed $z_{0 \mathrm{w}}$, averaged over all flux-runs where $A=0$. In the MIZ, this assumes these values to be representative of the water between ice floes. However, given the sensitivity of $z_{0}$ to wave amplitude (discussed in Sect. 4.1) and the attenuation of waves in the MIZ, these values may in fact be overestimates, leading to an overestimation of $C_{\mathrm{DN} 10}$.

With these discrepancies in mind, we define a second set of parameters, for which $\beta$ (a morphological exponent describing the dependence of $D_{\mathrm{i}}$ - the floe dimension - on $A$ ) is adjusted as well as $c_{\mathrm{e}}$. In L2012 a $\beta$ value of 1 is derived empirically by fitting their parametrisation for $D_{\mathrm{i}}$ (Eq. 17) to laser scanner observations from Fram Strait obtained by Hartmann et al. (1992) and Kottmeier et al. (1994). However, L2012 also found that by changing only $\beta$, their parametrisation was able to explain the variability in $C_{\mathrm{DN} 10}$ derived from various observational sources. For example, $\beta=1.4$ better represented observations made during REFLEX in the eastern Fram Strait (Hartmann et al., 1994), whilst $\beta=0.3$ better represented observations made in the Antarctic (Andreas et al., 1984) and the western Fram Strait (Guest and Davidson, 1987). Reducing $\beta$ has the effect of reducing $D_{\mathrm{i}}$ and consequently amplifying $C_{\mathrm{DN} 10}$ for all ice fractions, though particularly towards the higher fractions (though note that $D_{\mathrm{i}}$ will always eventually converge on $D_{\max }$ at $A=1$, according to Eq. 17). Consequently, setting a low value for $\beta$ helps explain particularly high drag coefficients at $A \approx 0.8$, justifying our second parameter set, for which we reduce $\beta$ to 0.2 (the lowest value recommended in L2012) in addition to further reducing $c_{\mathrm{e}}$ to 0.13 , to account for the reduction in $C_{\mathrm{DN} 10}$ across all values of $A$ which comes from reducing $\beta$. Figure 2 shows that these parameter settings (E2016B in Table 1) provide in general a marginally better fit to the complete data set than the E2016A settings.

The parametrisation is shown to also provide a generally good fit to subsets of the data. For example, the black and grey curves in Figs. 3 and 4 (the Barents Sea and Fram Strait subsets) denote as before the scheme using the E2016A and E2016B parameter settings respectively, and fit well despite the different ice morphologies and related contrasting values of $C_{\mathrm{DN} 10}$ at $A=1$. For the Barents Sea observations, the curve again passes through the interquartile range of all bins - though a little higher than the median values - both for $A_{\mathrm{a}}$ and $A_{\mathrm{SST}}$. For the Fram Strait observations there is good agreement in the case of $A_{\mathrm{a}}$, whilst for $A_{\mathrm{SST}}$ the form drag is generally overestimated. Finally, the parametrisation also provides an accurate representation of the Flight 181 observations (Fig. 9). It is important to note that the success of the scheme for different localities characterised by different ice conditions depends crucially on an accurate representation of $C_{\mathrm{DN} 10}$ at $A=1$. As mentioned in Sect. 2.3, in Eq. (12), $C_{\mathrm{DN} 10}$ at $A=1$ is provided by $C_{\mathrm{DN} 10 \mathrm{i}}$, defined in $\mathrm{L} 2012$ as the skin drag over sea ice. However, given that over rough, ridged sea ice, there is a form drag component in addition to skin drag, this term is more suitably expanded and expressed as the total (skin and form) drag over continuous sea ice, and considered to be a variable quantity, dependent on ice conditions.

As discussed in Sect. 4.2, our observations suggest that ice conditions in the MIZ characterised by relatively small, unconsolidated "pancake" ice floes at intermediate ice concentrations are characterised by higher drag coefficients than larger floes. The roughness extends locally to the highest ice concentrations, suggesting a case could be made for the use of $D_{\mathrm{i}}$ at intermediate ice fractions as a proxy for local MIZ surface roughness. Although this is partially implicit in the L2012 scheme in the sense that it accounts for smaller floes exerting greater form drag for a given ice concentration due to a greater frontal area (see Eq. 11), it seems likely given our observations that smaller floes are often associated with larger $C_{\mathrm{DN} 10}$ due to other, unaccounted-for reasons - for example, greater deformation and ridge-forming as a result of more frequent floe collisions due to smaller gaps between the floes or to floe advection caused by reduced ocean wave attenuation in areas of smaller floes. Note that this additional roughness corresponds to that discussed in the above paragraph as requiring inclusion in the $C_{\mathrm{DN} 10 \mathrm{i}}$ term in Eq. (12). Accounting for variability in the surface roughness of continuous sea ice has previously received some attention in 
the literature (Garbrecht et al., 2002; Andreas, 2011), though there is as yet no clear solution to this problem, and further progress in this area is beyond the scope of this study; see Conclusions for recommendations for future work.

\section{Implications and parametrisation recommendations}

It is clear that the physically based parametrisation of L2012 qualitatively fits our observations of surface drag (i.e. momentum exchange) over the MIZ very well. The recommended settings provided by L2012 (see Table 1) also quantitatively fit our observations well, although with some tuning of $c_{\mathrm{e}}$ (the effective resistance coefficient) and, optionally, $\beta$ (a sea-ice morphology exponent) this fit can be improved when compared to median $C_{\mathrm{DN} 10}$ values - see Figs. 2-4 and 9. We recommend two settings for the L2012 parametrisation: E2016A with $c_{\mathrm{e}}=0.17$ and $\beta=1$ and E2016B with $c_{\mathrm{e}}=0.1$ and $\beta=0.2$ (see Table 1). The E2016B setting enhances the negative skew of the $C_{\mathrm{DN} 10}$ distribution, increasing (decreasing) values at high (low) ice concentrations. These settings are illustrated as the black and grey lines in Figs. 2-4 and 9.

Our recommended L2012 settings are also plotted in Fig. 10 to allow a comparison against several other parametrisations used in numerical sea ice, climate or weather prediction models. Figure 10a shows the effective $10 \mathrm{~m}$ neutral drag coefficient for a grid square with the ice concentration indicated, i.e. it is an effective $C_{\mathrm{DN} 10}$ calculated proportionally for that mix of water and sea ice. To allow a direct comparison, the drag coefficient over open water, $C_{\mathrm{DN} 10 \mathrm{w}}$, is set to $1.1 \times 10^{-3}$ for all the algorithms. This value is appropriate for low-level winds of about $5 \mathrm{~m} \mathrm{~s}^{-1}$. It is simply chosen for illustrative purposes; similar illustrations result for other values of $C_{\mathrm{DN} 10 \mathrm{w}}$. Figure $10 \mathrm{~b}$ shows the effective roughness length - derived from the effective $C_{\mathrm{DN} 10}$ using Eq. (3) - as a function of sea-ice concentration. In addition to our recommended L2012 parametrisation settings, we also show those set as default in the sea-ice model CICE version 5.1 (see Tsamados et al., 2014; Hunke et al., 2015). In these, $c_{\mathrm{e}}=0.2, \beta=1$, and the ice flow sheltering constant $s=0.18$ (see Table 1). Note that there is a typographical error in Table 2 of Tsamados et al. (2014), where the parameters $c_{\mathrm{sf}}$ and $c_{\mathrm{sp}}$ are listed as equal to 0.2 (implying $c_{\mathrm{e}}=1$ ) when these should have been listed as equal to 1 (M. Tsamados, personal communication, 2015). When the corrected values are used, the CICE5.1 parametrisation matches our observations reasonably well (Fig. 10); although it does not account for the negative skew in the observations.

The ECMWF introduced a new parametrisation of surface drag over sea ice in cycle 41 of the Integrated Forecast System, which became operational on 12 May 2015. This introduces a variable sea-ice roughness length $z_{0 i}=\max \left[1,0.93(1-A)+6.05 e^{-17(A-0.5)^{2}}\right] \times 10^{-3}$ (see ECMWF documentation and Bidlot et al., 2014). This parametrised an increase in drag coefficient over the MIZ
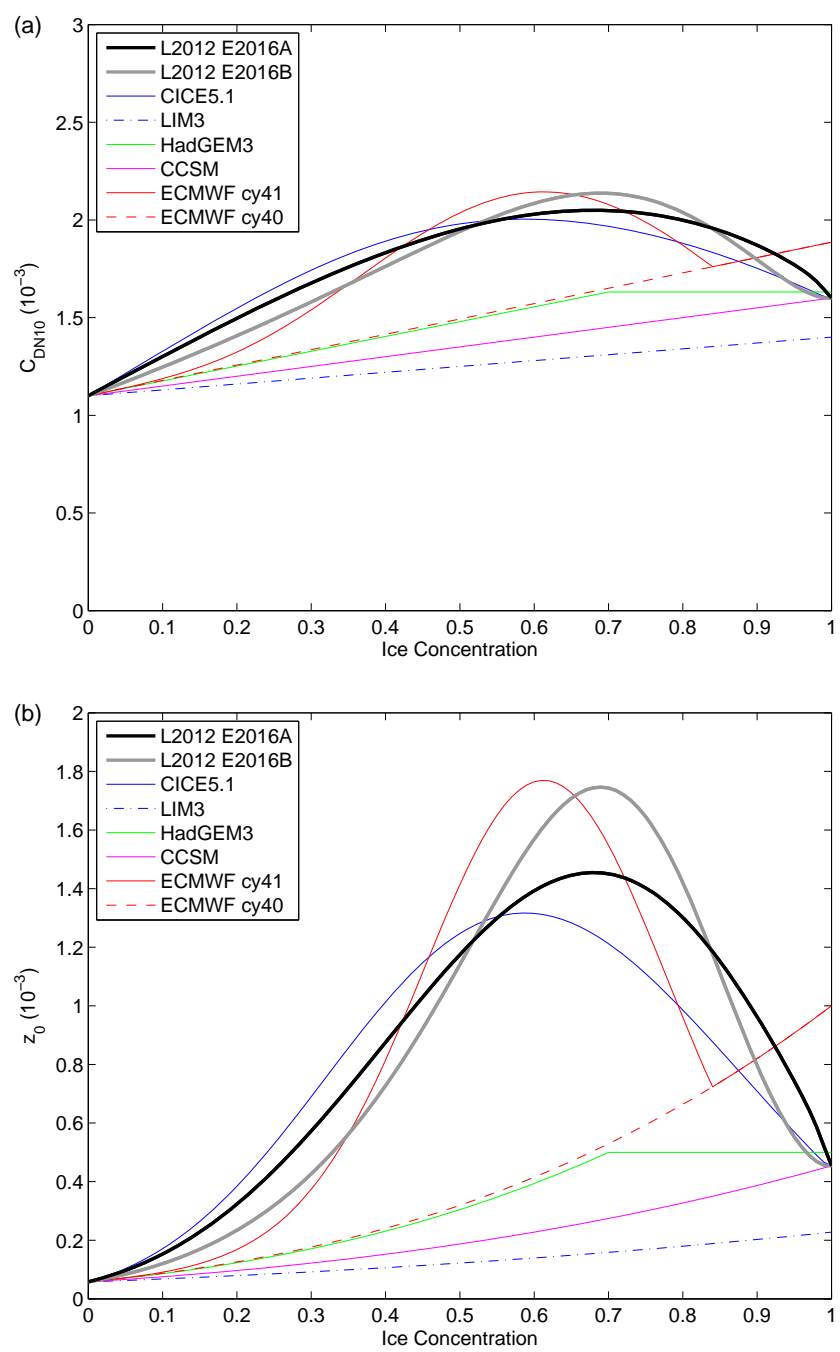

Figure 10. (a) Effective sea-ice drag coefficient and (b) derived effective roughness length as a function of ice concentration. Parametrisations shown are: Lüpkes et al. (2012) with settings as recommended here, namely $\mathrm{L} 2012 \mathrm{E} 2016 \mathrm{~A}$ with $c_{\mathrm{e}}=0.17$ and $\beta=1$ (black), and L2012 E2016B with $c_{\mathrm{e}}=0.1$ and $\beta=0.2$ (grey); the default L2012 settings used in CICE5.1 (blue) as described in Tsamados et al. (2014); the LIM3 interpolation (blue dash-dotted); the HadGEM3 default used in the Met Office Unified Model (green); the CCSM (and CAM5) interpolation (magenta); the ECMWF cycle 41 function (red) and the previous ECMWF cycle 40 interpolation (red dashed). See Table 1 for other L2012 settings.

which was inspired by the observations described in Andreas et al. (2010), so is consistent with L2012, and is close to our recommended settings for L2012 (Fig. 10).

All of the other parametrisations that are illustrated linearly interpolate between the drag coefficient over open water and constant values for $C_{\mathrm{DN} 10 \mathrm{i}}\left(\right.$ or $z_{0 \mathrm{i}}$ ). Consequently, they appear as straight lines in Fig. 10a. In the case of the ECMWF (cycle 40 and earlier) a constant $z_{0 \mathrm{i}}=1 \times 10^{-3} \mathrm{~m}$ (equivalent to $C_{\mathrm{DN} 10 \mathrm{i}}=1.89 \times 10^{-3}$ ) is set. This is also the 
default setting in the ECHAM climate model (see Lüpkes et al., 2013) and in the WRF numerical weather prediction model (Hines et al., 2015) - not shown in Fig. 10. In the CCSM (Community Climate System Model) and CAM5 (Community Atmospheric Model) $C_{\mathrm{DN} 10 \mathrm{i}}$ is set to $1.6 \times 10^{-3}$ (see Neale et al., 2010) and in LIM3 (the Louvain-la-Neuve Sea Ice Model) $C_{\mathrm{DN} 10 \mathrm{i}}$ is set to $1.5 \times 10^{-3}$ by default (see Vancoppenolle et al., 2012). Previous versions of the CICE sea-ice model also used a constant $z_{0 \mathrm{i}}$ set as $0.5 \times 10^{-3} \mathrm{~m}$. The Met Office use separate constant values for "the MIZ" (set at $A=0.7$ ) and "full sea ice" and then linearly interpolate. For their HadGEM3 climate model both $z_{0 \mathrm{i}}$ and $z_{0 \mathrm{MIZ}}$ are set to $0.5 \times 10^{-3} \mathrm{~m}$ for version 4.0 of their Global Sea Ice (GSI) configuration, as illustrated in Fig. 10; while for UKESM1, using GSI6.0, much higher values of $z_{0 \mathrm{i}}=3 \times 10^{-3} \mathrm{~m}$ and $z_{0 \mathrm{MIZ}}=100 \times 10^{-3} \mathrm{~m}$ are planned $(\mathrm{see}$ Rae et al., 2015). These are equivalent to $C_{\mathrm{DN} 10}$ values of 2.4 and $7.5 \times 10^{-3}$, respectively, so are not supported by our observations (see Fig. 2).

Examining Fig. 10, only the new (cycle 41) ECMWF parametrisation is qualitatively and quantitatively comparable to our recommended settings of the L2012 parametrisation. At present most numerical weather and climate prediction models do not have a maximum in drag coefficient over the MIZ. Consequently, they are not consistent with our observations, nor those of relevant previous compilations (e.g. Andreas et al., 2010; L2012).

It is clear that in configuring sea-ice models, $C_{\mathrm{DN} 10}$ over sea ice has commonly been used as a "tuning parameter". In fact it was specifically treated as such in the model sensitivity studies of, for example, Miller et al. (2006) and Rae et al. (2014). Miller et al. (2006) used the CICE model in standalone mode and varied three parameters widely, including $C_{\mathrm{DN} 10}$ between $0.3-1.6 \times 10^{-3}$, in an optimisation exercise. They found significant variability in extent and thickness across their simulations and concluded that determining an optimal set of parameters depended heavily on the forcing and validation data used. Rae et al. (2014) carried out a comprehensive fully coupled atmosphereocean-ice modelling sensitivity study, testing a large number of sea-ice-related parameter settings within their observational bounds. They found statistically significant sensitivity to the two sets of roughness length settings they tested: "CTRL" $\left(z_{0 \mathrm{i}}=0.5 \times 10^{-3}\right.$ and $\left.z_{0 \mathrm{MIZ}}=0.5 \times 10^{-3} \mathrm{~m}\right)$ and "ROUGH" $\left(z_{0 \mathrm{i}}=3 \times 10^{-3}\right.$ and $\left.z_{0 \mathrm{MIZ}}=100 \times 10^{-3} \mathrm{~m}\right)$. The rougher settings (also consistent with those in the Met Office global operational model) generally lead to simulations with a better sea-ice extent and volume compared to observations. However, we would note again that they are not consistent with our observations. Instead, our results would suggest these seemingly required large roughness lengths must be compensating for other deficiencies in the model configuration.

As discussed in Sect. 2, the exchange of momentum between the atmosphere and sea ice depends heavily on sea-ice morphology, thickness, and concentration. Prior to this study, observations of sea-ice drag were relatively limited, especially for the MIZ (i.e. for ice fractions $0<A<1$ ). Consequently, $C_{\mathrm{DN} 10}$ has not previously been well constrained by observations. Our data set doubles the number of observations available over the MIZ and is based on independent research platforms and analysis procedures to previously published data sets. Importantly, our results are broadly consistent with these previous observational compilations (e.g. Andreas et al., 2010; and L2012). This corroboration provides further confidence in our recommendations. In short, $C_{\mathrm{DN} 10}$ is now better constrained and we recommend that its parametrisation is consistent with our results.

\section{Conclusions}

We have investigated surface momentum exchange over the Arctic marginal ice zone using what is currently the largest set of aircraft observed data of its kind. Our results show that the momentum exchange is sensitive to sea ice concentration and morphology. Neutral $10 \mathrm{~m}$ surface drag coefficients $\left(C_{\mathrm{DN} 10}\right)$ are derived using the eddy covariance method and Monin-Obukhov theory, and two methods (which provide qualitatively similar results) are adopted for the derivation of ice fraction from our aircraft observations. After averaging $C_{\mathrm{DN} 10}$ data into ice fraction bins, the roughest surface conditions (characterised by the highest surface drag coefficients) are typically found in the ice fraction bins of 0.6 and 0.8 , while the smoothest surface conditions tend to be over open water and sometimes (dependent on sea-ice conditions) over continuous sea ice. Consequently, a good approximation for our observed $C_{\mathrm{DN} 10}$ as a function of ice concentration is provided by a negatively skewed distribution, in general agreement with previous observational studies (Hartman et al., 1994; Mai et al., 1996; Lüpkes and Birnbaum, 2005). However, we have found systematic differences in roughness between different locations. Over deformed, $10 \mathrm{~m}$ scale pancake ice in the Barents Sea, drag coefficients are considerably greater than over relatively homogeneous, non-deformed sea ice in Fram Strait. This dependence on ice morphology governs the magnitude and variability with ice fraction of $C_{\mathrm{DN} 10}$, and is likely to be the major cause of the considerable scatter in $C_{\mathrm{DN} 10}$ within each ice fraction bin.

Our observations have been used as a means to validate and tune one of the leading sea-ice drag parametrisation schemes - that of Lüpkes et al. (2012) i.e. L2012. This scheme provides $C_{\mathrm{DN} 10}$ as the sum of the drag over open water and continuous sea ice, and the form drag on ice floe edges, as given in Eq. (12) and repeated here: 


$$
\begin{aligned}
C_{\mathrm{DN} 10}= & (1-A) C_{\mathrm{DN} 10 \mathrm{w}}+A C_{\mathrm{DN} 10 \mathrm{i}} \\
& +A \frac{h_{\mathrm{f}}}{D_{\mathrm{i}}} S_{c}^{2} \frac{c_{\mathrm{e}}}{2}\left[\frac{\ln ^{2}\left(h_{\mathrm{f}} / z_{0 \mathrm{w}}\right)}{\ln ^{2}\left(10 / z_{0 \mathrm{w}}\right)}\right] .
\end{aligned}
$$

The final term on the right-hand side of this equation expresses the form drag component, and is derived following the theory of pressure drag exerted on a bluff body. This expression can be simplified following L2012 to be given as a function of only ice fraction $A$ and tuneable constants via Eqs. (15) to (18). In this simple form, the scheme provides a generally accurate representation of the observed distribution of $C_{\mathrm{DN} 10}$ as a function of sea-ice fraction. The agreement is optimized by adopting minor parameter adjustments to those originally recommended in L2012. These new settings are labelled as E2016A and E2016B in Table 1. E2016B arguably provides a better fit, though with values of $c_{\mathrm{e}}$ and $\beta$ which are at the limit of those physically plausible according to observations, whereas for E2016A these values are well within the confines of those observed. The scheme is shown to be robust, its success holding for subsets of our data (e.g. for each of the Barents Sea and Fram Strait locations, and for the single flight with the greatest number of data points) so long as it is anchored at $A=1$ by an observed value for $C_{\mathrm{DN} 10 \mathrm{i}}$.

Given the success of a sophisticated scheme such as that of L2012, the representation of sea-ice drag in many weather and climate models seems crude by comparison, with $C_{\mathrm{DN} 10}$ often set with little consideration of physical constraints and instead used as a tuning parameter. Our comprehensive observations provide the best means yet to constrain parametrisations of $C_{\mathrm{DN} 10}$ over the MIZ. They clearly imply that linearly interpolating between the open water surface drag $\left(C_{\mathrm{DN} 10 \mathrm{w}}\right)$ and a fixed sea-ice surface drag $\left(C_{\mathrm{DN} 10 \mathrm{i}}\right)$, as many parametrisations do, is not physically justified or representative. It is recommended that, as a minimum, parametrisations incorporate a peak in $C_{\mathrm{DN} 10}$ within the range $A=0.6$ to 0.8 (as a guide, in the 0.6 and 0.8 ice fraction bins of our observations, $C_{\mathrm{DN} 10}$ has a mean interquartile range of 1.25 to $2.85 \times 10^{-3}$ for all data - i.e. averaged across both bins for all panels in Fig. 2). Note that the precise peak value will vary with sea-ice morphology and, as found in Lüpkes and Gryanik (2015), stratification. Though sophisticated, the simplest form of the L2012 scheme is not computationally complex (having only one independent variable, $A$ ) and is recommended for adoption in weather and climate models.

The sensitivity of $C_{\mathrm{DN} 10}$ to ice fraction is now well established. Consequently, we recommend that future work focuses on the remaining major source of uncertainty: sensitivity to ice morphology. Our results suggest that the simplification of the L2012 scheme by parametrising floe dimension $\left(D_{\mathrm{i}}\right)$ and freeboard $\left(h_{\mathrm{f}}\right)$ in its expression for form drag on floe edges using $A$ provides sufficiently accurate results. Even so, as discussed above, floe size and ice morphology has a major impact on surface roughness and a more sophisticated representation of this should benefit sea-ice and climate simulations. In particular, this study demonstrates that setting an appropriate value of $C_{\mathrm{DN} 10}$ at $A=1$ is vital to the success of the L2012 parametrisation; given the observed variation with location (and hence ice conditions), a constant value for $C_{\mathrm{DN} 10}$ at $A=1$ is clearly unsuitable for simulations over large areas such as the entire Arctic. Here, we simply vary $C_{\mathrm{DN} 10 \mathrm{i}}$ in the $\mathrm{L} 2012$ scheme to reflect the observed location-dependent ice roughness at $A=1$. In sea-ice or climate models, perhaps $C_{\mathrm{DN} 10}$ at $A=1$ should be determined from sea-ice model output - for example, Tsamados et al. (2014) account for form drag on ice ridges. In operational models, perhaps $C_{\mathrm{DN} 10}$ at $A=1$ should be derived from sea-ice thickness observations (e.g. from CryoSat-2).

Our observations indicate that floe size is a governing factor in local variations of sea-ice roughness, even at the highest ice fractions. Consequently, to account for MIZ roughness associated with local ice conditions an option could be to accentuate the dependency of $C_{\mathrm{DN} 10}$ on floe size by expanding $C_{\mathrm{DN} 10 \mathrm{i}}$ to incorporate both the skin drag term and an additional "local" sea-ice form drag term which would be inversely proportional to a representative value of $D_{\mathrm{i}}$ (e.g. average $D_{\mathrm{i}}$ at a given ice fraction). To pursue such an approach and in general to provide clarity on this issue, future work would benefit greatly from incorporating aircraft laser scanner data, from which detailed morphological information on sea-ice conditions including floe shape, size, thickness, and roughness features such as ridging can be derived. 


\section{Appendix A: Quality control of momentum flux data}

In order to remove unsuitable data, a quality control procedure is utilised. This procedure follows previous studies (e.g. French et al., 2007; Petersen and Renfrew, 2009; Cook and Renfrew, 2015) and involves the visual inspection of a series of statistical diagnostics describing the variability of the perturbation wind components along each flux-run. "Bad" data points arise as a result of instrument malfunction or the violation of assumptions made in the methodology - notably that the turbulence is homogeneous along each run. The criteria that determine a "good" run are as follows:

The power spectra of the along-wind velocity component should have a well-defined decay slope (close to $k^{-5 / 3}$ for wavenumber $k$ ).

The total covariance of the along-wind velocity and vertical velocity should be far greater in magnitude than that of the cross-wind velocity and vertical velocity (which should be small), indicating alignment of the shear and stress vectors.

The cumulative summation of the covariance of the alongwind velocity and the vertical velocity should be close to a constant slope, indicating homogeneous covariance.

The cospectra of the covariance of the along-wind velocity and the vertical velocity should have little power at wavenumbers smaller than about $10^{-4} \mathrm{~m}^{-1}$, implying that mesoscale circulation features are not contributing significantly to the stress.

The cumulative summation of the cospectra should be shaped as ogives ("S"-shaped, with flat ends) implying that all of the wavenumbers that contribute to the total stress have been sampled and again that mesoscale features are not present.

Examples of "good" and discarded runs are illustrated in Fig. A1 (where the flux-run length is $\sim 9 \mathrm{~km}$ ). In the "good" example, there is little cross-wind spectral power and the cumulative summation has a near-constant slope indicating homogeneous turbulence structure along the length of the run. The "S"-shaped ogives and lack of power at small wavenumbers in the cospectra suggest that the turbulence is fully captured and that the signal is "unpolluted" by mesoscale circulations. For this typical case, the majority of energy is in eddies ranging from about 30 to $500 \mathrm{~m}$ in size, with no energy at all for wavelengths over $2500 \mathrm{~m}$. This information helps inform a suitable run duration, since it is important that the runs are long enough to capture several eddies of sizes at least across the dominant range of the spectrum. On the other hand, lengthening runs reduces the number of data points and increases the risk of sampling organised mesoscale features instead of pure turbulence.

Note that five different flux-run durations were trialled using a sample of the data set. These durations varied between the two aircraft (according to their mean flight speed) in order that they correspond to lengths of approximately $3,6,9$, 12 , and $15 \mathrm{~km}$. Using the above quality control procedure it
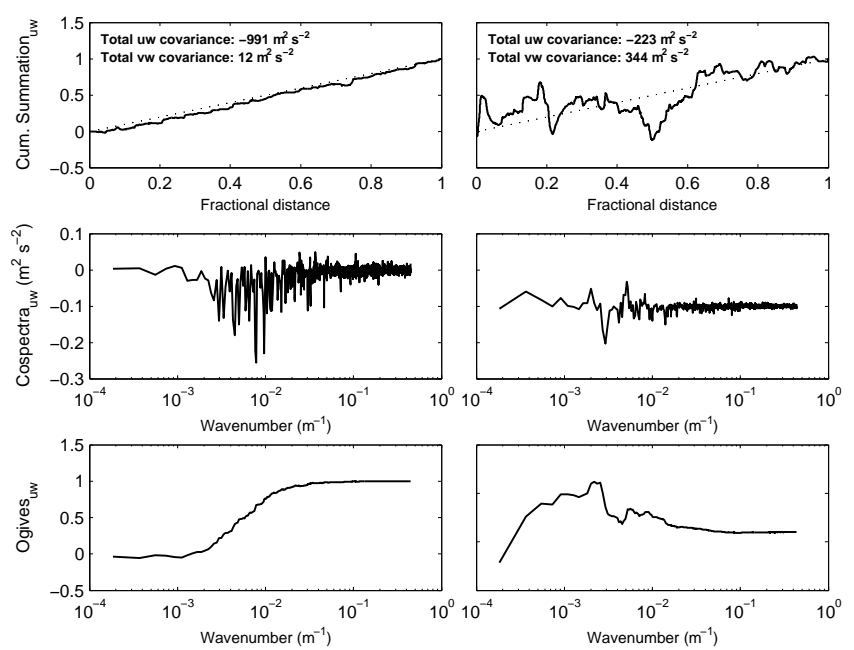

Figure A1. Quality control diagnostics for momentum flux $\left(u^{\prime} w^{\prime}\right)$. Left column shows a "good" run (Flight 181, leg 2, run 7); right column shows a "bad" run (Flight 181, leg 5, run 11). The rows show (top) the cumulative summation of $u^{\prime} w^{\prime}$ versus distance along the run, (middle) the frequency weighted cospectra, and (bottom) the ogives (integrated cospectra) both as a function of wavenumber. The cumulative summation is normalised by the total covariance and the ogives by the total cospectra.

was ascertained that a run length of $9 \mathrm{~km}$ procures the highest quality data and so is used here. This is comparable to Weiss et al. (2010) and Fiedler et al. (2010) who used 8 and $8.8 \mathrm{~km}$; and a little shorter than Petersen and Renfrew (2009) and Cook and Renfrew (2015) who used $12 \mathrm{~km}$.

\section{Appendix B: Deriving ice fraction $A$ from the aircraft observations}

Two different remote sensing techniques are used to derive estimates of ice fraction $A$ from the aircraft observations, using proxies based on albedo and surface temperature. These techniques rely on sea ice being more reflective and colder than sea water. In both approaches the proxy is linked to $A$ using two tie points: one at the no ice transition between open water and the onset of ice $(A \rightarrow 0)$ and another at the all ice transition between continuous ice and the appearance of some water $(A \rightarrow 1)$. This allows an estimate of ice concentration for each data point, accounting for the fact that each measurement may sample multiple floes. Ice fraction is then provided for each measurement by

$$
A_{X}= \begin{cases}0 & \text { for } X \leq X_{A \rightarrow 0} \\ \frac{\left(X-X_{A \rightarrow 0}\right)}{\left(X_{A \rightarrow 1}-X_{A \rightarrow 0}\right)} & \text { for } X_{A \rightarrow 0}<X<X_{A \rightarrow 1} \\ 1 & \text { for } X \geq X_{A \rightarrow 1},\end{cases}
$$


where $X$ is the instantaneous value of the proxy and $X_{A \rightarrow 0}$ and $X_{A \rightarrow 1}$ are the tie points for the no ice transition and the all ice transition respectively. Note that the recorded aircraft data $(1 \mathrm{~Hz}$ for the relevant diagnostics $)$ and approximate mean aircraft speed for straight and level runs (60 and $100 \mathrm{~m} \mathrm{~s}^{-1}$ for MASIN and FAAM respectively) translates to each measurement point sampling over a distance of 60 and $100 \mathrm{~m}\left(\gg D_{\min }\right)$, respectively. We average over the $9 \mathrm{~km}$ run to obtain a representative ice fraction $A$.

Albedo is calculated from measurements of the upward and downward components of the shortwave radiative flux: $a=\mathrm{SW}_{\mathrm{U}} / \mathrm{SW}_{\mathrm{D}} \cdot A_{\mathrm{a}}$ is derived using tie points $a_{A \rightarrow 0}=0.15$ and $a_{A \rightarrow 1}=0.85$, which were chosen following careful review of video footage from four flights (two from each aircraft: MASIN 182 and 185; FAAM B761 and B765). It is accepted that these tie points are approximate and may vary depending on ice conditions; however, there is good agreement between the flights for which video footage was available. While these values are broadly consistent with textbook albedo values (e.g. Curry and Webster, 1999), $a_{A \rightarrow 0}$ is towards the upper end of the expected range, so an alternative albedo-derived ice fraction, $A_{\mathrm{a} 2}$, is calculated using $a_{A \rightarrow 0}=0.07$ (matching that used to approximate freezing point in the Weddell Sea in Weiss et al., 2012). A limitation of the albedo approach is that $A_{\mathrm{a}}$ will be underestimated for semi-transparent thin ice, as measurements will be affected by the lower albedo of the sea water below.

In the SST approach, a lower tie point of $\operatorname{SST}_{A \rightarrow 0}=$ $-3.4^{\circ} \mathrm{C}$ was ascertained following inspection of the flight videos. It is recognised that this value is lower than might be expected given typical ocean salinity. Indeed, salinity measurements made by the RRS James Clark Ross as part of the ACCACIA field campaign suggests typical values of between 30 and 35 (a little fresher than is typical, likely as a result of spring melt), implying a freezing point of about $-1.8^{\circ} \mathrm{C}$. It is possible this discrepancy may be due to a cool skin being measured by the aircraft's radiometers. In the vicinity of the MIZ, cool skin temperatures are likely to be a result of the top few centimetres of the ocean containing small fragments of ice (e.g. frazil) as was observed during the flights. In addition, the radiatively driven "cool skin effect" (Fairall et al., 1996) may also contribute. To account for this uncertainty, we also calculate two different ice fractions using the SST approach; $A_{\mathrm{SST}}$ uses the lower value suggested by the video footage $\left(-3.4^{\circ} \mathrm{C}\right)$, while $A_{\text {SST2 }}$ uses the theoretical value based on observed salinities $\left(-1.8^{\circ} \mathrm{C}\right)$.

Due to the thin-ice problem, the SST approach is arguably more suitable than the albedo approach at prescribing the onset of ice with a suitable fixed no ice transition (so long as a suitable value is determined). However, there is a fundamental problem in assigning an SST all ice transition that is suitable across multiple flights. This is because the surface temperature over continuous ice varies greatly according to the atmospheric conditions. Using a fixed value for $\mathrm{SST}_{A \rightarrow 1}$ could therefore lead to inconsistencies between flights under

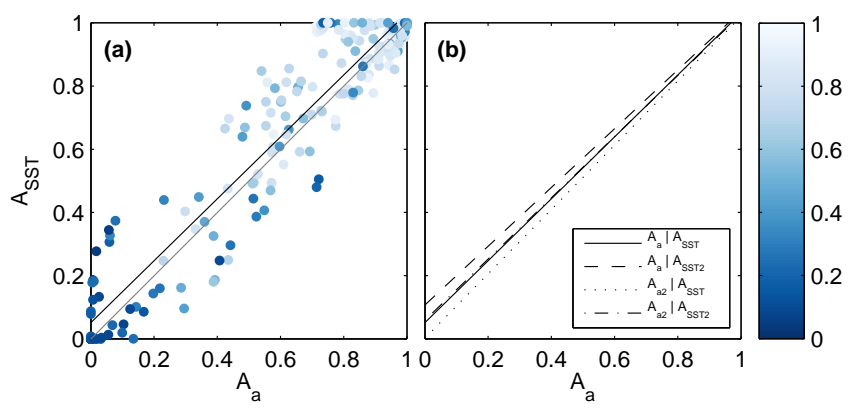

Figure B1. Ice fraction calculated from aircraft observations using the surface temperature method $\left(A_{\mathrm{SST}}\right)$ plotted against that using the albedo method $\left(A_{\mathrm{a}}\right)$. (a) Data points for every run (dots) and linear regression (black line) are shown, using the default criteria for both methods $\left(a_{A \rightarrow 0}=0.15\right.$ and $\left.\mathrm{SST}_{A \rightarrow 0}=-3.4^{\circ} \mathrm{C}\right)$. Dots are coloured according to the OSTIA satellite-derived ice fraction, and the one-to-one line (grey) is shown. (b) Linear regressions of all combinations of observation-derived $A_{\mathrm{a}}$ and $A_{\mathrm{SST}}$.

different weather conditions; for example overestimating $A$ in the case of particularly cold ice floes as $A \rightarrow 1$. Consequently, in the SST approach an adjustment of the $\mathrm{SST}_{A \rightarrow 1}$ tie point using albedo is used, which provides a robust estimate of $\mathrm{SST}_{A \rightarrow 1}$ for any atmospheric conditions. For each flight, $\mathrm{SST}_{A \rightarrow 1}$ is set equal to the median SST value for all flux-run data points where $a$ is within the range $a_{A \rightarrow 1} \pm 0.05$, i.e. between 0.8 and 0.9 . Using this criterion, $\mathrm{SST}_{A \rightarrow 1}$ ranges from -23.6 to $-9.6^{\circ} \mathrm{C}$ between flights, with this variability being a strong function of latitude (the colder values being for the northernmost flights). The suitability of this method is demonstrated by the high level of internal consistency in SST values within the $a_{A \rightarrow 1} \pm 0.05$ range for each flight, with a mean standard deviation (averaged across all flights) of only $1.3^{\circ} \mathrm{C}$.

Figure B1 compares the ice fractions estimated using the albedo and SST methods. It shows that there is a near oneto-one relationship between $A_{\mathrm{a}}$ and $A_{\mathrm{SST}}$, with a correlation coefficient of 0.94 , a root-mean-square error of 0.12 and a bias error of 0.03 for the video-assigned values of $a_{A \rightarrow 0}$ and $\mathrm{SST}_{A \rightarrow 0}$. Linear regressions with the alternative tie point values show only a small sensitivity to these settings. Overall, Fig. B1 demonstrates that our methodologies are sound and that the estimates of ice fraction are robust. 
Table B1. Notation.

\begin{tabular}{|c|c|}
\hline$A$ & ice fraction \\
\hline$\alpha$ & Charnock constant \\
\hline$b$ & smooth-flow constant for the Charnock relation \\
\hline$\beta$ & $\begin{array}{l}\text { constant exponent describing the dependence of } \\
D_{\mathrm{i}} \text { on } A\end{array}$ \\
\hline$C_{\mathrm{D}}$ & drag coefficient \\
\hline$C_{\mathrm{DN} 10}$ & $\begin{array}{l}\text { drag coefficient for neutral stability at a height } \\
\text { of } 10 \mathrm{~m}\end{array}$ \\
\hline$C_{\mathrm{DNf} 10}$ & neutral form drag coefficient at a height of $10 \mathrm{~m}$ \\
\hline$C_{\mathrm{DNi} 10}$ & $\begin{array}{l}\text { neutral drag coefficient over sea ice at a height } \\
\text { of } 10 \mathrm{~m}\end{array}$ \\
\hline$C_{\mathrm{DNw} 10}$ & $\begin{array}{l}\text { neutral drag coefficient over sea water at a } \\
\text { height of } 10 \mathrm{~m}\end{array}$ \\
\hline$c_{\mathrm{e}}$ & effective resistance coefficient \\
\hline$c_{\mathrm{s}}$ & ice floe shape parameter \\
\hline$c_{\mathrm{W}}$ & $\begin{array}{l}\text { fraction of the available force acting on each } \\
\text { floe }\end{array}$ \\
\hline$D_{\mathrm{i}}$ & cross-wind floe dimension \\
\hline$D_{\min }, D_{\max }$ & $\begin{array}{l}\text { minimum and maximum cross-wind floe di- } \\
\text { mension }\end{array}$ \\
\hline$D_{\mathrm{w}}$ & distance between floes \\
\hline$f_{\mathrm{d}}$ & $\begin{array}{l}\text { total force acting on the frontal areas of ice floes } \\
\text { within the area }\end{array}$ \\
\hline$h_{\mathrm{f}}$ & freeboard height of floes \\
\hline$h_{\min }, h_{\max }$ & $\begin{array}{l}\text { minimum and maximum freeboard height of } \\
\text { floes }\end{array}$ \\
\hline$\kappa$ & von Karman constant $(0.4)$ \\
\hline$N$ & number of floes in area $S_{\mathrm{t}}$ \\
\hline$\rho$ & air density \\
\hline$s$ & ice floe sheltering function constant \\
\hline$S_{\mathrm{c}}$ & ice floe sheltering function \\
\hline$S_{\mathrm{t}}$ & domain area of $N$ floes \\
\hline$\tau$ & momentum flux \\
\hline$\tau_{\mathrm{d}}$ & momentum flux related to form drag \\
\hline$U$ & horizontal wind speed \\
\hline$U_{10 \mathrm{~N}}$ & adjusted $10-\mathrm{m}$ neutral horizontal wind speed \\
\hline$u_{*}$ & friction velocity \\
\hline$v$ & dynamic viscosity \\
\hline$\varphi$ & Monin-Obukhov stability correction \\
\hline$z_{0}$ & roughness length \\
\hline$z_{0 \mathrm{i}}$ & roughness length for sea ice \\
\hline$z_{0 \mathrm{w}}$ & roughness length for open water \\
\hline
\end{tabular}


Acknowledgements. This work was funded by the NERC (grant numbers NE/I028653/1, NE/I028858/1, and NE/I028297/1) as part of its Arctic Research Programme. We thank the FAAM and MASIN pilots, crew, flight planners, and mission scientists; Christof Lüpkes, Jean Bidlot, Jamie Rae, and John Edwards for discussions; and Barbara Brooks for providing photographs.

Edited by: H. Wernli

\section{References}

Andreas, E. L.: A relationship between the aerodynamic and physical roughness of winter sea ice, Q. J. Roy. Meteor. Soc., 137, 927-943, 2011.

Andreas, E. L., Tucker, W. B., and Ackley, S. F.: Atmospheric boundary-layer modification, drag coefficient, and surface heat flux in the Antarctic marginal ice zone, J. Geophys. Res.-Oceans, 89, 649-661, doi:10.1029/JC089iC01p00649, 1984.

Andreas, E. L., Horst, T. W., Grachev, A. A., Persson, P. O. G., Fairall, C. W., Guest, P. S., and Jordan, R. E.: Parametrizing turbulent exchange over summer sea ice and the marginal ice zone, Q. J. Roy. Meteor. Soc., 136, 927-943, doi:10.1002/qj.618, 2010.

Arya, S. P. S.: Contribution of form drag on pressure ridges to the air stress on Arctic ice, J. Geophys. Res., 78, 7092-7099, doi:10.1029/JC078i030p07092, 1973.

Arya, S. P. S.: A drag partition theory for determining the large-scale roughness parameter and wind stress on the Arctic pack ice, J. Geophys. Res., 80, 3447-3454, doi:10.1029/JC080i024p03447, 1975.

Banke, E. G. and Smith, S. D.: Wind stress over ice and over water in the Beaufort Sea, J. Geophys. Res., 76, 7368-7374, doi:10.1029/JC076i030p07368, 1971.

Beljaars, A. C. M. and Holtslag, A. A. M.: Flux parameterization over land surfaces for atmospheric models, J. Appl. Meteorol., 30, 327-341, doi:10.1175/15200450(1991)030<0327:FPOLSF>2.0.CO;2, 1991.

Bidlot, J.-R., Keeley S., and Mogensen, K.: Towards the Inclusion of Sea Ice Attenuation in an Operational Wave Model. Proceedings of the 22nd IAHR International Symposium on ICE 2014 (IAHR-ICE 2014), available at: http://rpsonline.com.sg/ iahr-ice14/html/org.html, 2014.

Birnbaum, G. and Lüpkes C.: A new parameterization of surface drag in the marginal sea ice zone, Tellus 54A, 107-123, doi:10.1034/j.1600-0870.2002.00243.x, 2002.

Castellani, G., Lüpkes, C., Hendricks, S., and Gerdes, R.: Variability of Arctic sea-ice topography and its impact on the atmospheric surface drag, J. Geophys. Res.-Oceans, 119, 6743-6762, doi:10.1002/2013JC009712, 2014

Claussen, M.: Area-averaging of surface fluxes in a neutrally stratified, horizontally inhomogeneous atmospheric boundary layer, Atmos. Environ., 24A, 1349-1360, 1990.

Cook, P. A. and Renfrew, I. A.: Aircraft-based observations of airsea turbulent fluxes around the British Isles, Q. J. Roy. Meteor. Soc., 141, 139-152, doi:10.1002/qj.2345, 2015.

Curry, J. A. and Webster, P. J.: Thermodynamics of atmospheres and oceans, Academic Press, 65, 471 pp., Elsevier, New York, 1999.
Dyer, A. J.: A review of flux-profile relationships, Bound.-Lay. Meteorol., 7, 363-372, doi:10.1007/BF00240838, 1974.

ECMWF: Working Group Report: ECMWFWWRP/THORPEX Polar Prediction Workshop, available at: http://www.ecmwf.int/sites/default/files/elibrary/2013/13913ecmwf-wwrpthorpex-workshop-polar-prediction-workinggroups-report.pdf) (last access: 10 March 2004), 2013.

Fairall, C. W., Bradley, E. F., Godfrey, J. S., Wick, G. A., Edson, J. B., and Young, G. S.: Cool-skin and warm-layer effects on sea surface temperature, J. Geophys. Res.-Oceans, 101, 1295-1308, doi:10.1029/95JC03190, 1996.

Fairall, C. W., Bradley, E. F., Hare, J. E., Grachev, A. A., and Edson, J. B.: Bulk parameterization of air-sea fluxes: Updates and verification for the COARE algorithm, J. Climate, 16, 571-591, doi:10.1175/1520-0442(2003)016<0571:BPOASF>2.0.CO;2, 2003.

Fiedler, E. K., Lachlan-Cope, T. A., Renfrew, I. A., and King, J. C.: Convective heat transfer over thin ice covered coastal polynyas, J. Geophys. Res., 115, C10051, doi:10.1029/2009JC005797, 2010.

French, J. R., Drennan, W. M., Zhang, J. A., and Black, P. G.: Turbulent fluxes in the hurricane boundary layer. Part I: Momentum flux, J. Atmos. Sci., 64, 1089-1102, doi:10.1175/JAS3887.1, 2007.

Garbrecht, T., Lüpkes, C., Augstein, E., and Wamser, C.: The influence of a sea ice ridge on the low level air flow, J. Geophys. Res., 104, 24499-24507, doi:10.1029/1999JD900488, 1999.

Garbrecht, T., Lüpkes, C., Hartmann, J., and Wolff, M.: Atmospheric drag coefficients over sea ice - validation of a parameterisation concept, Tellus A, 54, 205-219, doi:10.1034/j.16000870.2002.01253.x, 2002.

Garman, K. E., Hill, K. A., Wyss, P., Carlsen, M., Zimmerman, J. R., Stirm, B. H., Carney, T. Q., Santini, R., and Shepson, P. B.: An Airborne and Wind Tunnel Evaluation of a Wind Turbulence Measurement System for Aircraft-Based Flux Measurements, J. Atmos. Ocean Tech., 23, 1696-1708, doi:10.1175/JTECH1940.1, 2006.

Guest, P. S. and Davidson, K. L.: The effect of observed ice conditions on the drag coefficient in the summer East Greenland Sea marginal ice zone, J. Geophys. Res. Oceans (1978-2012), 92, 6943-6954, doi:10.1029/JC092iC07p06943, 1987.

Hanssen-Bauer, I. and Gjessing, Y. T.: Observations and model calculations of aerodynamic drag on sea ice in the Fram Strait, Tellus 40A, 151-161, doi:10.1111/j.1600-0870.1988.tb00413.x, 1988.

Hartmann, J., Kottmeier, C., and Wamser, C.: Radiation and Eddy Flux Experiment 1991: (REFLEX I), Berichte zur Polarforschung (Reports on Polar Research), 105, 1992.

Hartmann, J., Kottmeier, C., Wamser, C., and Augstein, E.: Aircraft measured atmospheric momentum, heat and radiation fluxes over Arctic sea ice, in: The polar oceans and their role in shaping the global environment, 443-454, doi:10.1029/GM085p0443, 1994.

Hines, K. M., Bromwich, D. H., Bai, L., Bitz, C. M., Powers, J. G., and Manning, K. W.: Sea Ice Enhancements to Polar WRF, Mon. Weather Rev., 143, 2363-2385, doi:10.1175/MWR-D-1400344.1, 2015

Hunke, E. C, Lipscomb, W. H., Turner, A. K., Jeffery, N., and Elliott, S.: CICE: the Los Alamos Sea Ice Model documentation and software user's manual, Version 5.1, 116 pp., avail- 
able at: http://oceans11.lanl.gov/trac/CICE (last access: 29 January 2016), 2015.

Johannessen, O. M. and Foster, L. A.: A note on the topographically controlled oceanic polar front in the Barents Sea, J. Geophys. Res.-Oceans, 83, 4567-4571, doi:10.1029/JC083iC09p04567, 1978.

King, J. C., Lachlan-Cope, T. A., Ladkin, R. S., Weiss, A.: Airborne measurements in the stable boundary layer over the Larsen Ice Shelf, Antarctica, Bound.-Lay. Meteorol., 127, 413-428, doi:10.1007/s10546-008-9271-4, 2008.

Kohout, A. L., Williams, M. J. M., Dean, S. M., and Meylan, M. H.: Storm-induced sea-ice breakup and the implications for ice extent, Nature, 509, 604-607, doi:10.1038/nature13262, 2014.

Kottmeier, C., Hartmann, J., and Wamser, C.: Radiation and eddy flux experiment 1993:(REFLEX II). Berichte zur Polarforschung (Reports on Polar Research), 133, 1994.

Kwok, R. and Rothrock, D. A.: Decline in Arctic sea ice thickness from submarine and ICESat records: 1958-2008, Geophys. Res. Lett., 36, L15501, doi:10.1029/2009GL039035, 2009.

Lüpkes, C. and Birnbaum, G.: Surface drag in the Arctic marginal sea-ice zone: A comparison of different parameterisation concepts, Bound.-Lay. Meteorol., 117, 179-211, doi:10.1007/s10546-005-1445-8, 2005.

Lüpkes, C. and Gryanik, V. M.: A stability-dependent parametrization of transfer coefficients for momentum and heat over polar sea ice to be used in climate models, J. Geophys. Res. Atmos., 120, 552-581, doi:10.1002/2014JD022418, 2015.

Lüpkes, C., Gryanik, V. M., Hartmann, J., and Andreas, E. L.: A parametrization, based on sea ice morphology, of the neutral atmospheric drag coefficients for weather prediction and climate models, J. Geophys. Res., 117, D13112, doi:10.1029/2012JD017630, 2012.

Lüpkes, C., Gryanik, V. M., Rösel, A., Birnbaum, G., and Kaleschke, L.: Effect of sea ice morphology during Arctic summer on atmospheric drag coefficients used in climate models, Geophys. Res. Lett., 40, 446-451, doi:10.1002/grl.50081, 2013.

Mai, S., Wamser, C., and Kottmeier, C.: Geometric and aerodynamic roughness of sea ice, Bound.-Lay. Meteorol., 77, 233-248, doi:10.1007/BF00123526, 1996.

Markus, T., Stroeve, J. C., and Miller, J.: Recent changes in Arctic sea ice melt onset, freezeup, and melt season length, J. Geophys. Res., 114, C12024, doi:10.1029/2009JC005436, 2009.

Miller, P. A., Laxon, S. W., Feltham, D. L., and Cresswell, D. J.: Optimization of a sea ice model using basinwide observations of Arctic sea ice thickness, extent, and velocity, J. Climate, 19, 1089-1108, doi:10.1175/JCLI3648.1, 2006.

Neale, R. B., Chen, C. C., Gettelman, A., Lauritzen, P. H., Park, S., Williamson, D. L., Rasch, P. J., Vavrus, S. J., Taylor, M. A., Collins, W. D., Zhang, M., and Shian-Jiann, L.: Description of the NCAR Community Atmospheric Model (CAM 5.0), NCAR technical note, NCAR/TN-486 + STR, 268 pp., 2010.

Newman, S. M., Smith, J. A., Glew, M. D., Rogers, S. M., and Taylor, J. P.: Temperature and salinity dependence of sea surface emissivity in the thermal infrared, Q. J. Roy. Meteor. Soc., 131, 2539-2557, doi:10.1256/qj.04.150, 2005.

Notz, D.: Challenges in simulating sea ice in Earth System Models, Wiley Interdiscip, Rev. Clim. Change, 3, 509-526, doi:10.1002/wcc.189, 2012.
Overland, J. E.: Atmospheric boundary layer structure and drag coefficients over sea ice, J. Geophys. Res.-Oceans, 90, 9029-9049, doi:10.1029/JC090iC05p09029, 1985.

Pellerin, P., Ritchie, H., Saucier, F. J., Roy, F., Desjardins, S., Valin, M., and Lee, V.: Impact of a two-way coupling between an atmospheric and an ocean-ice model over the Gulf of St. Lawrence, Mon. Weather Rev., 132, 1379-1398, doi:10.1175/15200493(2004)132<1379:IOATCB>2.0.CO;2, 2004.

Petersen, G. N. and Renfrew, I. A.: Aircraft-based observations of air-sea fluxes over Denmark Strait and the Irminger Sea during high wind speed conditions, Q. J. Roy. Meteor. Soc., 135, 20302045, doi:10.1002/qj.355, 2009.

Rae, J. G. L., Hewitt, H. T., Keen, A. B., Ridley, J. K., Edwards, J. M., and Harris, C. M.: A sensitivity study of the sea ice simulation in the global coupled climate model, HadGEM3, Ocean Model., 74, 60-76, doi:10.1002/qj.355, 2014.

Rae, J. G. L., Hewitt, H. T., Keen, A. B., Ridley, J. K., West, A. E., Harris, C. M., Hunke, E. C., and Walters, D. N.: Development of the Global Sea Ice 6.0 CICE configuration for the Met Office Global Coupled model, Geosci. Model Dev., 8, 2221-2230, doi:10.5194/gmd-8-2221-2015, 2015.

Renfrew, I. A., Moore, G. W. K., Guest, P. S., and Bumke, K.: A comparison of surface layer and surface turbulent flux observations over the Labrador Sea with ECMWF analyses and NCEP reanalyses, J. Phys. Oceanogr., 32, 383-400, 2002.

Renfrew, I. A., Petersen, G. N., Outten, S., Sproson, D., Moore, G. W. K., Hay, C., Ohigashi, T., Zhang, S., Kristjánsson, J. E., Føre, I., Ólafsson, H., Gray, S. L., Irvine, E. A., Bovis, K., Brown, P. R. A., Swinbank, R., Haine, T., Lawrence, A., Pickart, R. S., Shapiro, M., and Woolley, A.: The Greenland flow distortion experiment, B. Am. Meteorol. Soc., 89, 1307-1324, 2008.

Roy, F., Chevallier, M., Smith, G., Dupont, F., Garric, G., Lemieux, J.-F., Lu, Y., and Davidson, F.: Arctic sea ice and freshwater sensitivity to the treatment of the atmosphere-iceocean surface layer, J. Geophys. Res.-Oceans., 120, 4392-4417, doi:10.1002/2014JC010677, 2015.

Schröder, D., Vihma, T., Kerber, A., and Brümmer, B.: On the parameterisation of Turbulent Surface Fluxes Over Heterogeneous Sea Ice Surfaces, J. Geophys. Res., 108, 3195 doi:10.1029/2002JC001385, 2003.

Smith, G. C., Roy, F., and Brasnett, B.: Evaluation of an operational ice-ocean analysis and forecasting system for the Gulf of St Lawrence, Q. J. Roy. Meteor. Soc., 139, 419-433, doi:10.1002/qj.1982, 2013.

Sorteberg, A. and Kvingedal, B.: Atmospheric forcing on the Barents Sea winter ice extent, J. Climate, 19, 4772-4784, 2006.

Stössel, A., Cheon, W.-G., and Vihma, T.: Interactive momentum flux forcing over sea ice in a global ocean GCM, J. Geophys. Res., 113, C05010, doi:10.1029/2007JC004173, 2008.

Stull, R. B.: An introduction to boundary layer meteorology, Kluwer Academic Publishers, Dordrecht, doi:10.1007/978-94-009-30278, 1988.

Tsamados, M., Feltham, D. L., Schroeder, D., Flocco, D., Farrell, S. L., Kurtz, N., Laxon, S. L., and Bacon, S.: Impact of Variable Atmospheric and Oceanic Form Drag on Simulations of Arctic Sea Ice, J. Phys. Oceanogr., 44, 1329-1353, doi:10.1175/JPO-D13-0215.1, 2014.

Uttal, T., Curry J. A., McPhee, M. G., Perovich, D. K., Moritz, R. E., Maslanik, J. A., Guest, P. S., Stern, H. L., Moore, J. A., 
Turenne, R., Heiberg, A., Serreze, M. C., Wylie, D, P., Persson, P. O. G., Paulson, C. A., Halle, C., Morison, J. H., Wheeler, P. A., Makshtas, A.,Welch, H., Shupe, M. D., Intrieri, J. M., Stamnes, K., Lindsey, R. W., Pinkel, R., Pegau, W. S., Stanton, T. P., and Grenfeld, T. C.: Surface Heat Budget of the Arctic Ocean, B. Am. Meteorol. Soc., 83, 255-275, doi:10.1175/15200477(2002)083<0255:SHBOTA>2.3.CO;2, 2002.

Vancoppenolle, M., Bouillon, S., Fichefet, T., Goosse, H., Lecomte, O., Morales Maqueda, M. A. and Madec, G.: The Louvainla-Neuve sea Ice Model Users Guide, 89 pp., available at: http://www.elic.ucl.ac.be/repomodx/lim/ (last access: 29 January 2016), 2012.

Vihma, T.: Subgrid Parameterization of Surface Heat and Momentum Fluxes over Polar Oceans, J. Geophys. Res., 100, 2262522646, doi:10.1029/95JC02498, 1995.
Wadhams, P., Squire, V. A., Goodman, D. J., Cowan, A. M., and Moore, S. C.: The attenuation rates of ocean waves in the marginal ice zone, J. Geophys. Res.-Oceans, 93, 6799-6818, doi:10.1029/JC093iC06p06799, 1988.

Weiss, A. I., King, J., Lachlan-Cope, T., and Ladkin, R.: On the effective aerodynamic and scalar roughness length of Weddell Sea ice, J. Geophys. Res., 116, D19119, doi:10.1029/2011JD015949, 2011.

Weiss, A. I., King, J. C., Lachlan-Cope, T. A., and Ladkin, R. S.: Albedo of the ice covered Weddell and Bellingshausen Seas, The Cryosphere, 6, 479-491, doi:10.5194/tc-6-479-2012, 2012. 